\title{
4. GEOPHYSICAL SITE SURVEY RESULTS NEAR DEEP SEA DRILLING PROJECT SITES 417 and 418 IN THE CENTRAL ATLANTIC OCEAN
}

\author{
Philip D. Rabinowitz, Lamont-Doherty Geological Observatory, Columbia University, Palisades, New York \\ Hartley Hoskins, Woods Hole Oceanographic Institution, Woods Hole, Massachusetts \\ and \\ Steven M. Asquith, Lamont-Doherty Geological Observatory, Columbia University, Palisades, New York
}

We present geophysical measurements collected in an approximate degree and one-half square surrounding DSDP Sites 417 and 418 of D.V. Glomar Challenger. The data are presented in the form of a navigation chart of the track lines (Figure 1), a contoured bathymetric chart (Figure 2), profiles of the geomagnetic anomaly along track (Figure 3), and normal-incidence singlechannel seismic reflection profiler records (Figures 4 through 18). The measurements were collected in part as an IPOD site survey aboard U.S.N.S. Lynch (Hoskins and Groman, 1976). The purpose of the survey was to locate drill sites for crustal drilling in the vicinity of magnetic anomaly $M 0(\sim 108$ m.y.B.P. $)$ at about $25^{\circ} \mathrm{N}$. The other measurements presented were obtained aboard R.V. Vema, R. V. Robert D. Conrad, H.M.S. Snellius, and D.V. Glomar Challenger (see Table 1 for list of cruises).

The bounds of the survey area are $24^{\circ} 00^{\prime}$ to $25^{\circ} 40^{\prime} \mathrm{N}$ and $67^{\circ} 00^{\prime}$ to $69^{\circ} 40^{\prime} \mathrm{W}$, as shown in the navigation chart of Figure 1. Cruise names, dates, and times are annotated along the ships' tracks to key into the seismic reflection profile given in Figures 4 through 18. Sea-floor soundings were obtained on all cruises and used to construct the bathymetric map given in Figure 2. Total geomagnetic field measurements were also obtained on all cruises shown in Figure 1. Some magnetic anomaly profiles had to be omitted from Figure 3 for clarity in display.

Most of the sea floor in the survey area lies at a depth between 5500 and 5600 meters. There are several prominences in the east and northeast as shallow as 4400 meters. The sediment cover is typically 100 to 200 meters in the area of smoother basement topography in the western half of the survey area. The contoured representation of the topography in the sedimentblanketed areas is good. Over the survey area, the mean basement depth is about 200 to 300 meters deeper to the west and southwest, and is typically about 6000 to 6200 meters in the vicinity of anomaly $M 0$. Basement relief in the vicinity of $M 0$ is 200 to 500 meters, a little less to the west and more to the east.

Due to the sharpness of basement prominences with respect to the spacing of the track lines and the wide beam of the sounder even in this densely surveyed area, the contouring is inadequate to sufficiently identify and delineate the shape of the prominences. The prominences appear to be related to two fracture zones trending approximately $120^{\circ}$ through the area (Schouten and
TABLE 1

Sources of Seismic Reflection Profiles Employed in this Study of the Survey Area Encompassing DSDP Sites 417 and 418

\begin{tabular}{lll}
\hline \multicolumn{1}{c}{ Ship } & \multicolumn{1}{c}{ Cruise } & Year \\
\hline U.S.N.S. Lynch & a & 1976 \\
R. V. Vema & 1802 b,c & 1961 \\
& 1902 b,c & 1963 \\
& 2609 & 1969 \\
R. V. Robert D. Conrad & 1003 & 1966 \\
& 1112 & 1967 \\
& 1903 & 1975 \\
& 1904 & 1975 \\
& 1906 & 1976 \\
& 2001 & 1976 \\
& 2012 & 1977 \\
D. V. Glomar Challenger & Leg 51 & 1976 \\
& Leg 52 & $1976-77$ \\
& Leg 53 & 1977 \\
H. M. S. Snellius & c,d & 1965 \\
\hline
\end{tabular}

a $30-\mathrm{kHz}$ sparker used as sound source for seismic profiling.

${ }^{\mathrm{b}}$ Explosives used as sound source.

${ }^{c}$ Celestial navigation used, all other cruises used satellite navigation.

${ }^{d}$ Seismic data not available. All other cruises used an airgun as sound source for seismic reflection profiling. Magnetics and bathymetry data collected on all cruises.

Klitgord, in preparation) and lie mainly to the east of magnetic anomaly $M 0$.

To delineate the location of the magnetic source bodies in the crust giving rise to the shorter wavelength anomalies, the long wavelength components were removed using the reference field of Cain et al. (1964) or the I.G.R.F. 1965.0 of Fabiano and Peddie (1969). A constant of approximately 500 gammas was added to the observed anomalies on some profiles because the reference fields were, in general, too high in the survey area.

The magnetic anomalies are presented in profile format using the vessels' track line as a zero gamma baseline. Data are plotted perpendicular to the track line with the positive anomalies on the north- or east-facing side of the track. The identifications of the Mesozoic magnetic anomalies shown in Figure 3 were aided by the more regional data base given in Vogt et al., 1971, and 
Schouten and Klitgord, 1977. The magnetic anomaly identification numbers were adapted from Larson and Hilde, 1975. Anomalies $M 0$ to $M 4$ correlate very well in the survey region. Three offsets or fracture zones are observed which trend approximately normal to the magnetic lineation pattern. The magnetic lineation patterns on either side of the southernmost fracture zone are well defined showing a left-lateral offset across the fracture zone of $\sim 14 \mathrm{~km}$ (7.5 n.mi.). The sense and amount of displacement of the two northernmost fracture zones are not well determined.

There are no distinctive topographic or basement features that can be traced along the entire length of the three fracture zones. Much of the topographic relief in the area appears to be associated with the fracture zones. The location of the source bodies responsible for the magnetic anomalies is shown superimposed on the magnetic map in Figure 3. Due to the inclination and declination of the earth's field, of the source and its dip (Schouten and McCamy, 1972), the magnetic anomalies are located approximately $7 \mathrm{~km}$ east of the axis of the source bodies. Holes drilled at Site 417 were drilled near the center of the reversely magnetized block responsible for anomaly $M 0$; holes drilled at Site 418 were drilled near the boundary between $M 0$ and the Cretaceous quiet zone (long period of predominantly normal geomagnetic polarity).

We show in Figures 4 through 18 all of the seismic reflection profiler records collected in the survey area. The seismic data for each cruise are presented chronologically and are keyed to the navigation in Figure 1. Note that the chronological presentation results in the left side of the profile being east or west, or north or south depending on the heading of the ship. It was not practical to construct a sediment isopach map for two reasons: the survey grid was not as dense as the scale of much of the basement topography; and picking the basement interface is difficult in many areas due to the scattered returns from topography off the trackline. This difficulty is well borne out by the difference in the sediment thickness between Sites 417 and 418 and in the post-site survey of Purdy and Ewing (this volume).

\section{ACKNOWLEDGMENTS}

We wish to thank the officers, scientists and crew aboard the research vessels that collected the data presented here.

This work was supported under a subcontract from the Deep Sea Drilling Project UC-NSF-C482-2 and OCE 7621786. The R.V. Vema and the R.V. Robert D. Conrad data were collected under NSF grant GA 27281 and Office of Naval Research contract N00014-67-A-0108-0004.

\section{REFERENCES}

Cain, J. C., Daniels, W. F., Hendricks, S. J., and Jensen, D., 1964. Computation of the main geomagnetic field from spherical harmonic expansion, Goddard Space Flight Center Publ. X-611-64-316, p. 47.

Fabiano, E. G. and Peddie, N. U., 1969. Grid values of total magnetic intensity, I.G.R.F., 1965 U.S. ESSA Tech. Rept., v. 38, p. 55 .

Hoskins, H. and Groman, R. C., 1976. Informal Report of Surveys at IPOD sites AT 2.2 and AT 2.3, Woods Hole Oceanographic Institution (unpublished manuscript), Woods Hole, Mass.

Larson, R. L. and Hilde, T. W. C., 1975. A revised time scale of magnetic reversals for the Early Cretaceous and late Jurassic, Geophys. Res., v. 80, p. 2586-2594.

Matthews, D. J., 1939. Tables of the velocity of sound in pure water and sea water for use in echo sounding and sound ranging: London (Her Majesty's Stationery Office).

Pitman, W. C., III, Larson, R. L., and Herron, E. M., 1974. The age of the ocean basins: Boulder, Colorado (Geol. Soc. Am.).

Schouten, H. and Klitgord, K., 1977. Mesozoic magnetic anomalies, western North Atlantic, U.S.G.S. Misc. Field Studies Map MF-915.

in preparation. Mesozoic spreading and reconstructions of the central North Atlantic.

Schouten, H. and McCamy, K., 1972. Filtering marine magnetic anomalies, J. Geophys. Res., v. 77, p. 7089-7099.

Vogt, P. R., Anderson, C. N., and Bracey, D. R., 1971. Mesozoic magnetic anomalies, seafloor spreading and geomagnetic reversals in the southwestern North Atlantic, J. Geophys. Res., v. 76, p. 4796-4823. 


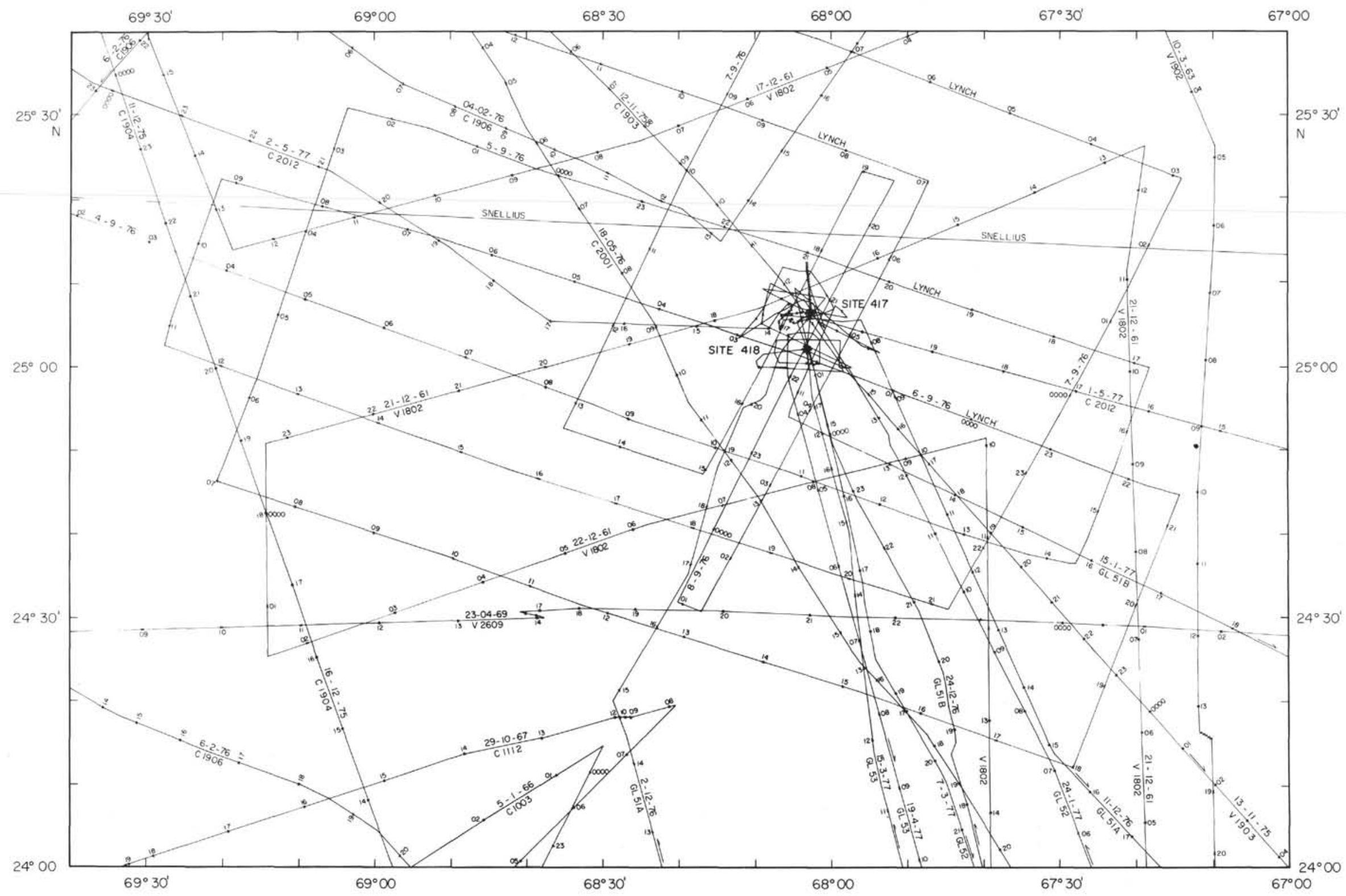

Figure 1. Map showing location of all ships' tracks in survey area, as well as DSDP Site 417 and 418 site locations. Times, dates, and cruise identification are annotated along ship's tracks. 


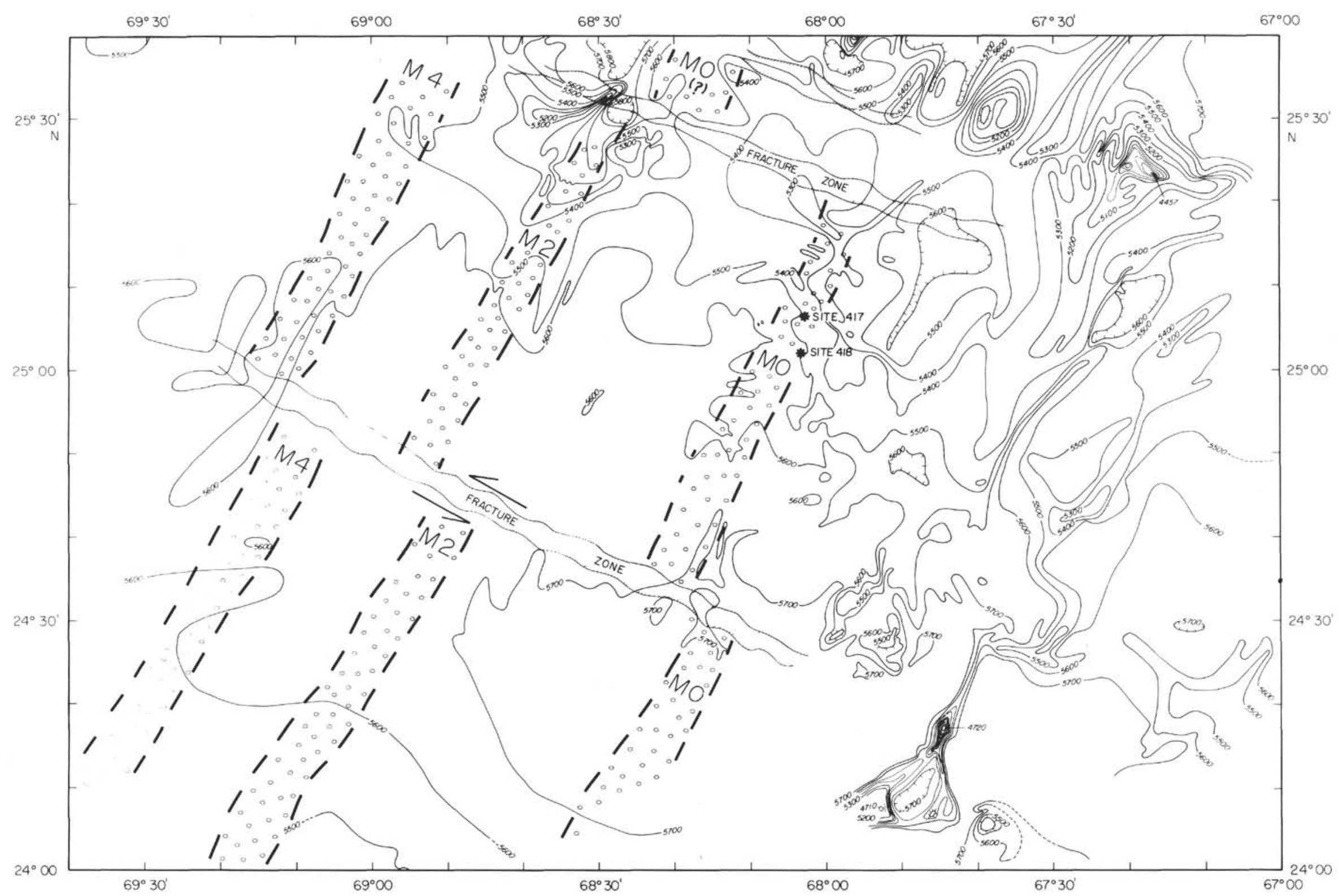

Figure 2. Bathymetric chart contoured at 100-meter intervals. Sounding corrected for velocity of sound in seawater after Matthews (1939). Magnetic source bodies and fracture zone locations from Figure 3. Control given in Figure 1. 


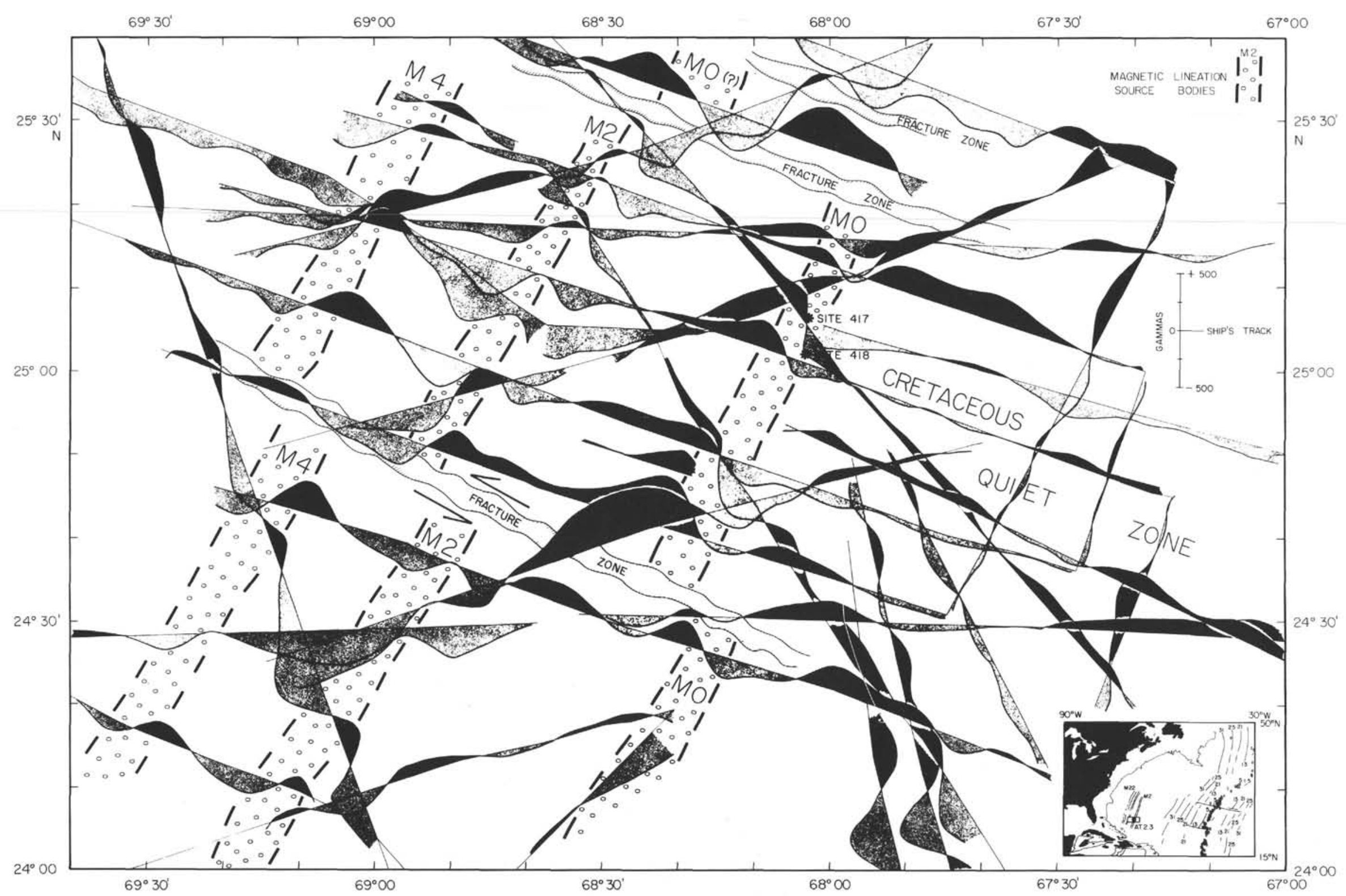

Figure 3. Magnetic anomaly profiles along ships' track. Location of source bodies responsible for magnetic anomalies, fracture zones, and DSDP Sites 417 and 418 are also illustrated. Note that source bodies are displaced westward from axis of magnetic anomalies. Insert from Pitman et al. (1974). 


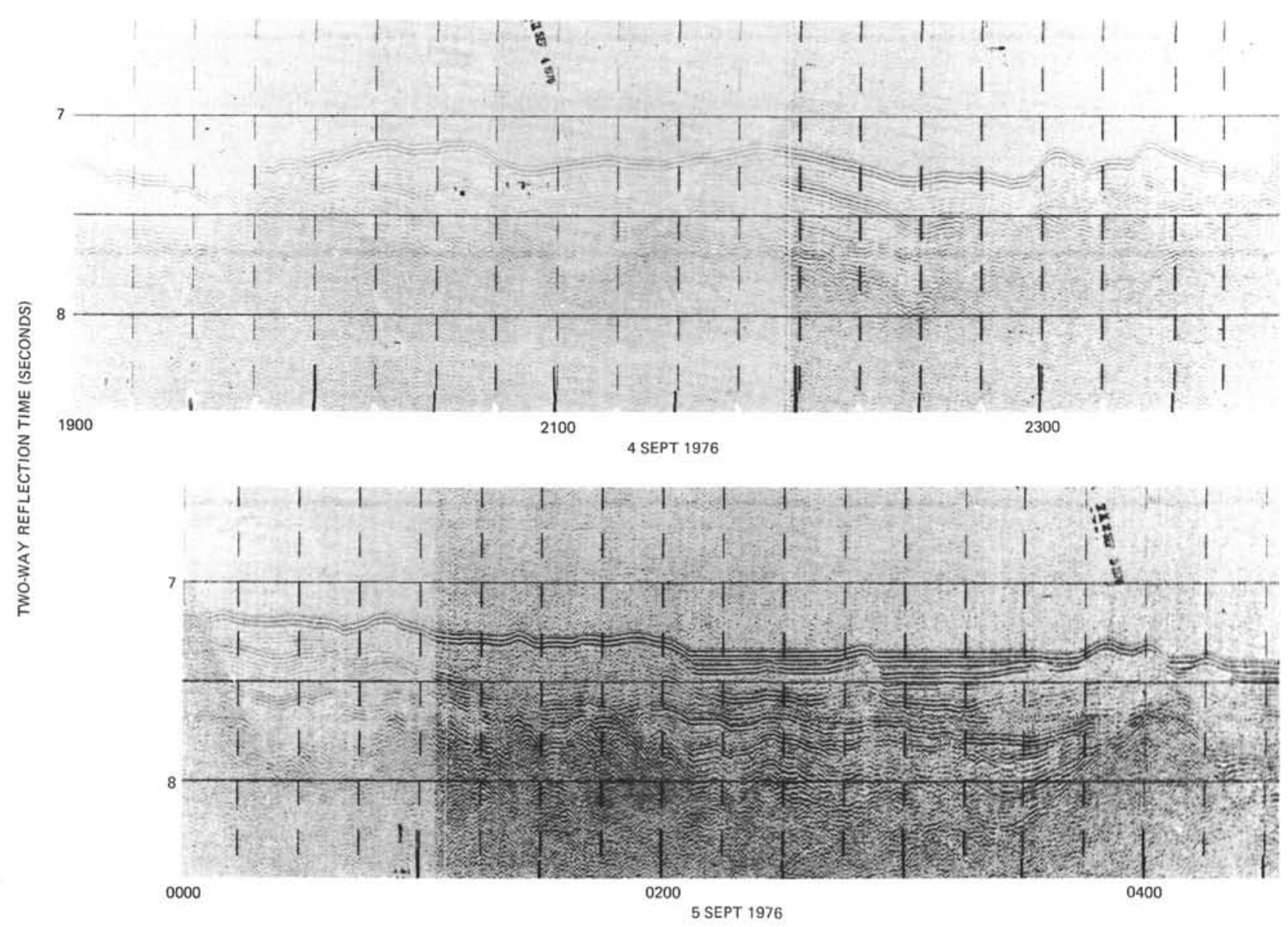

Figure 4 (a-m). Seismic reflection profiler records collected aboard U.S.N.S. Lynch. Vertical scale in seconds of two-way reflection time. Horizontal scale given in time along ships' tracks and is keyed to Figure 1. 30 Kj sparker fired at 10-s intervals used as sound source for reflection profiling. 


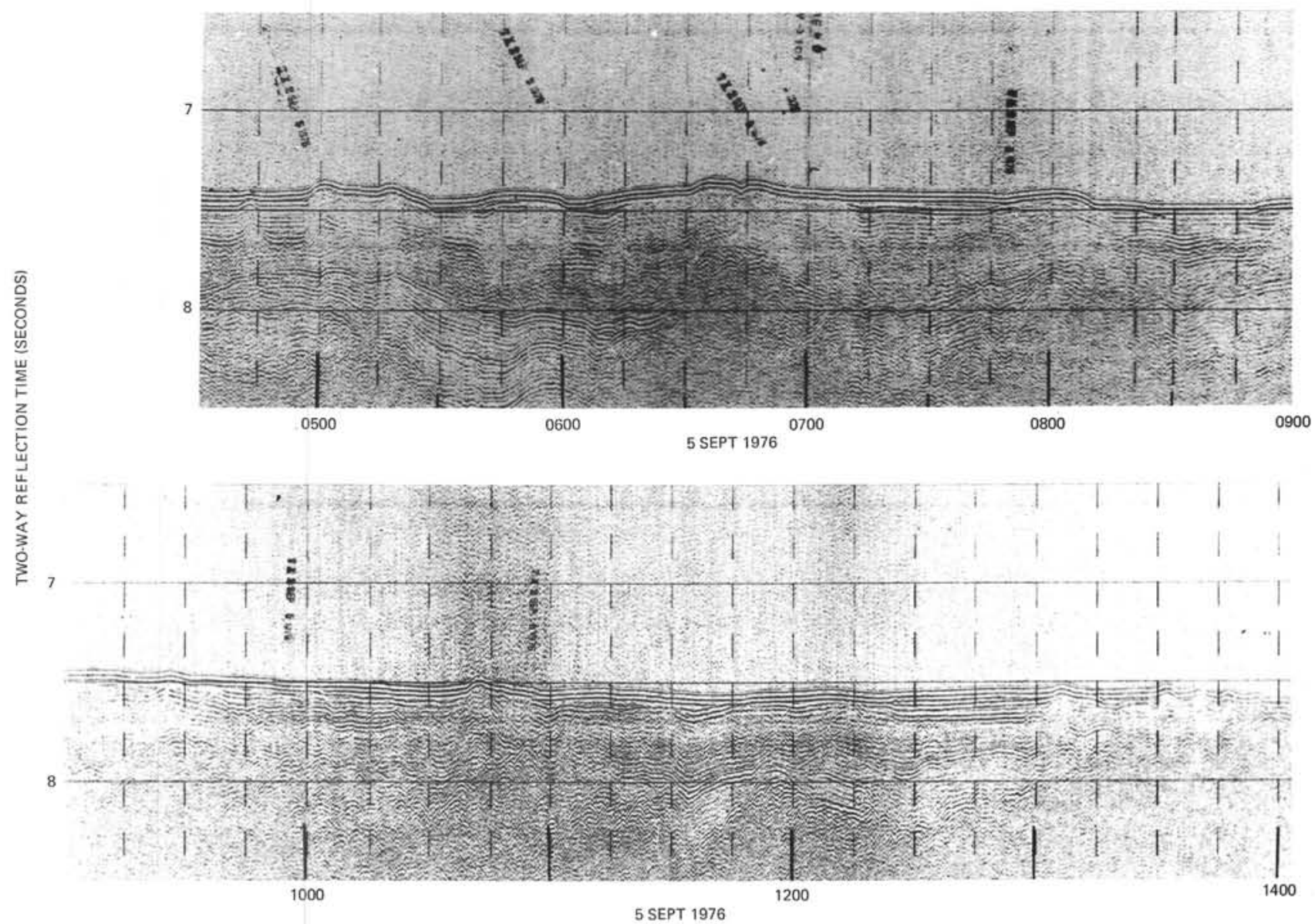

Figure 4. (Continued). 


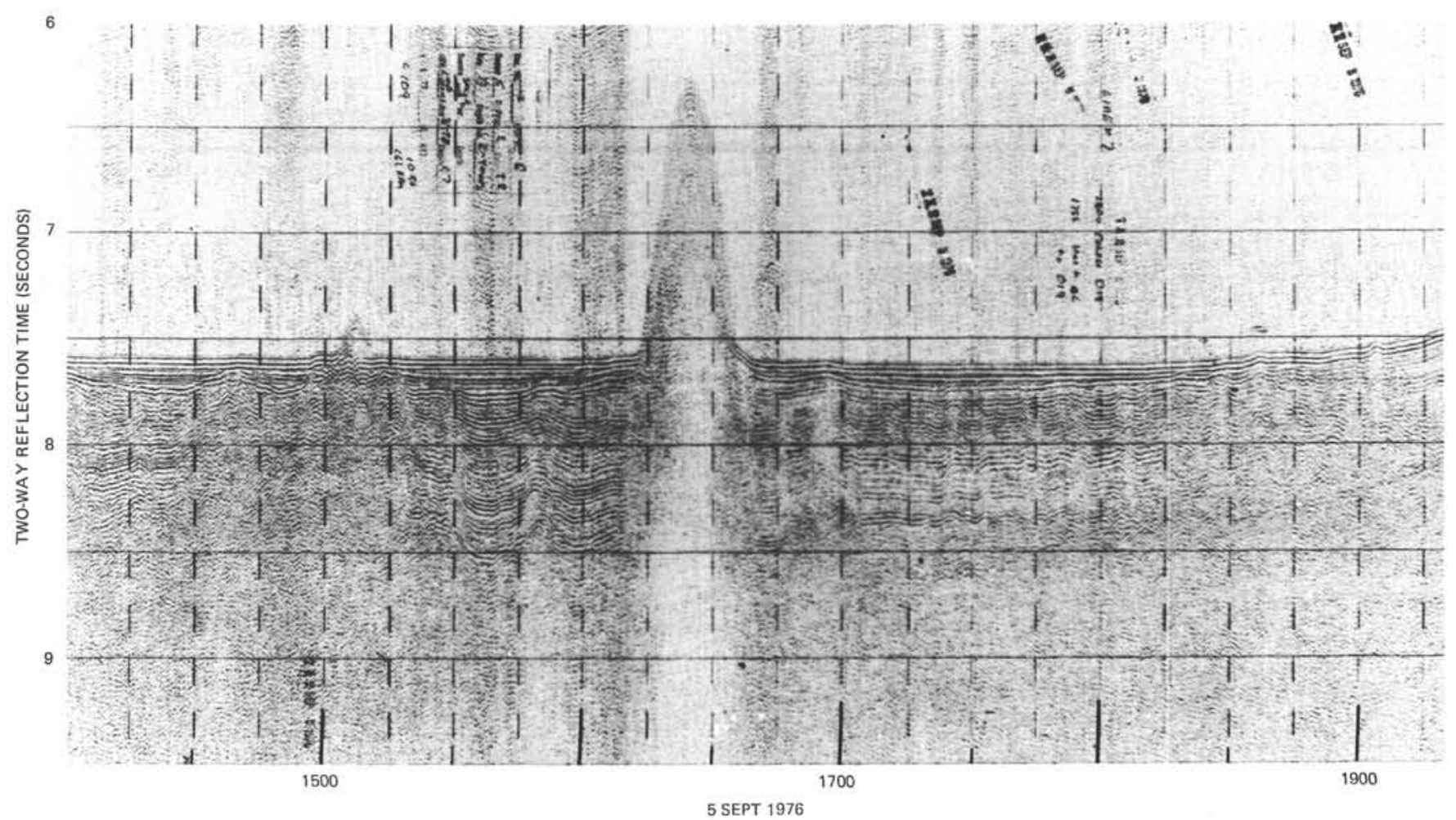

Figure 4. (Continued). 


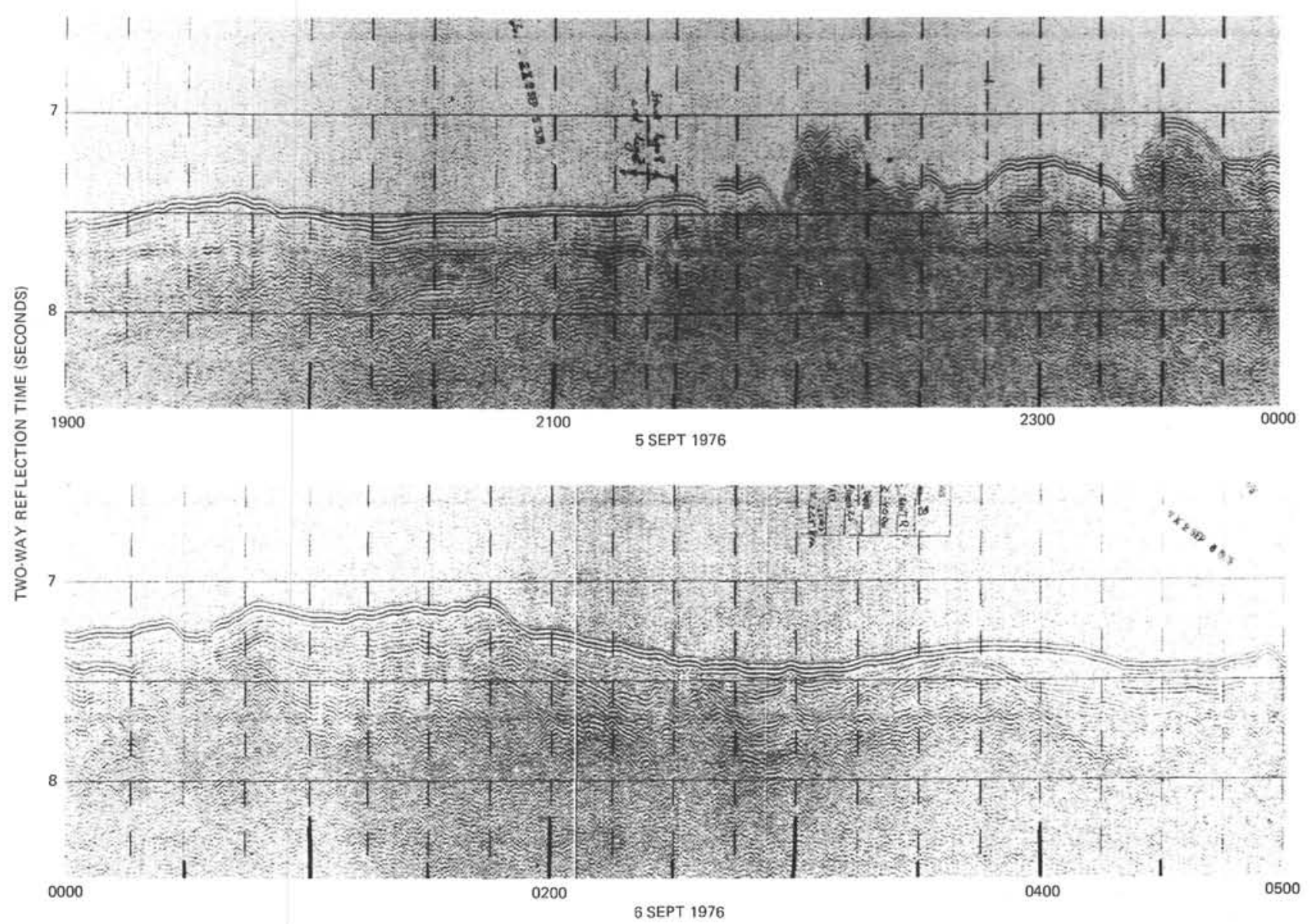

Figure 4. (Continued). 


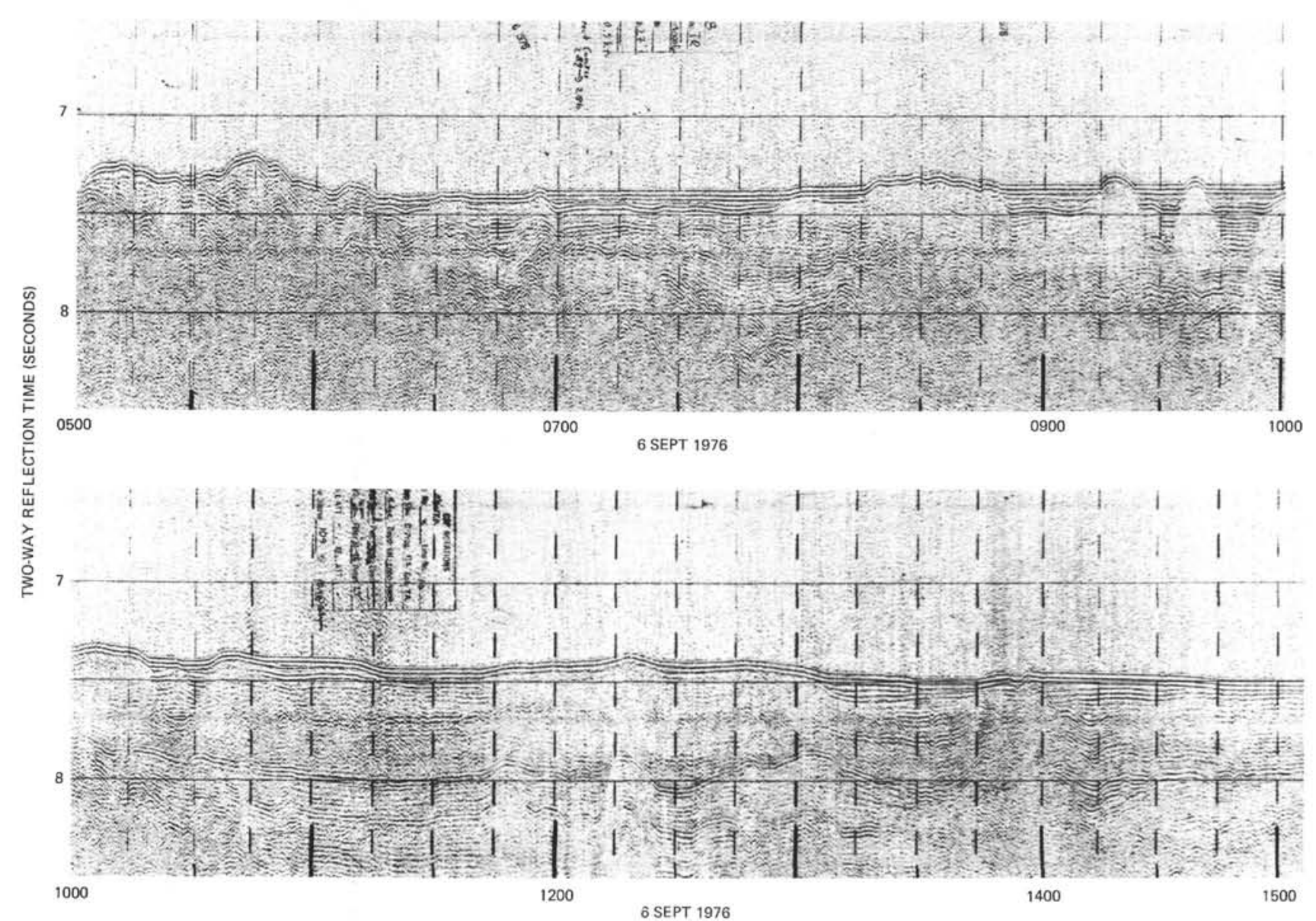

Figure 4. (Continued). 


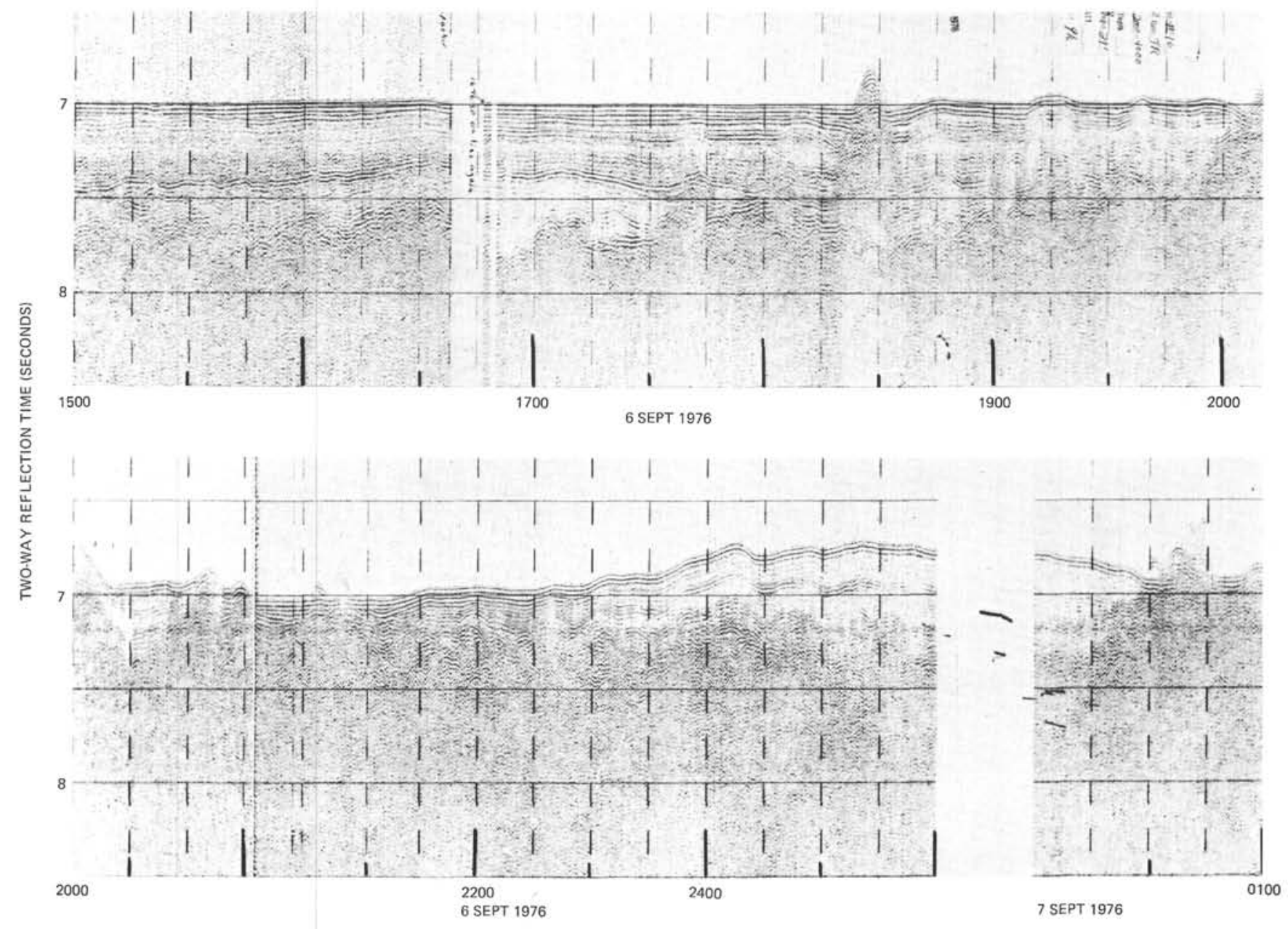

Figure 4. (Continued). 


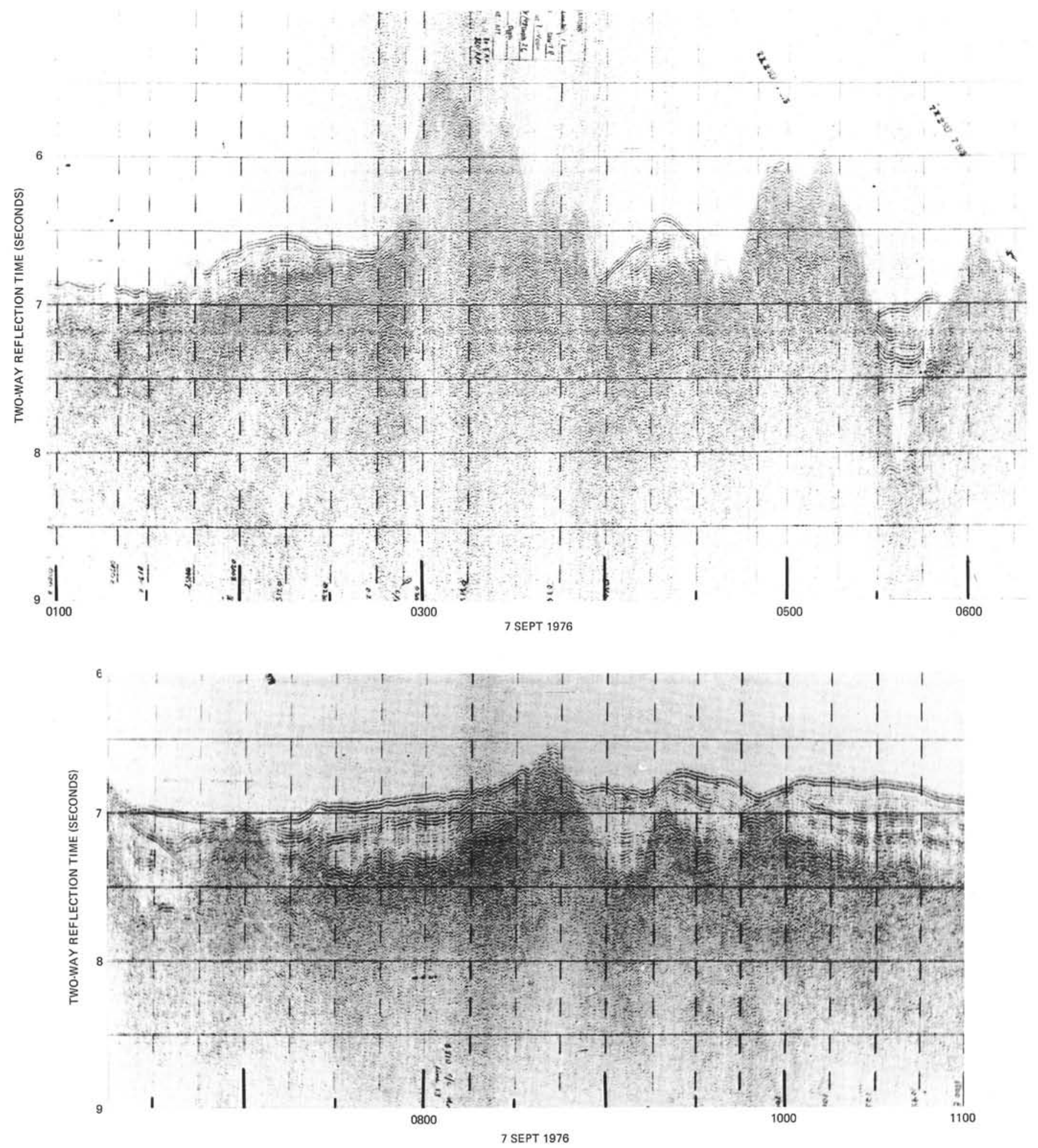

Figure 4. (Continued). 

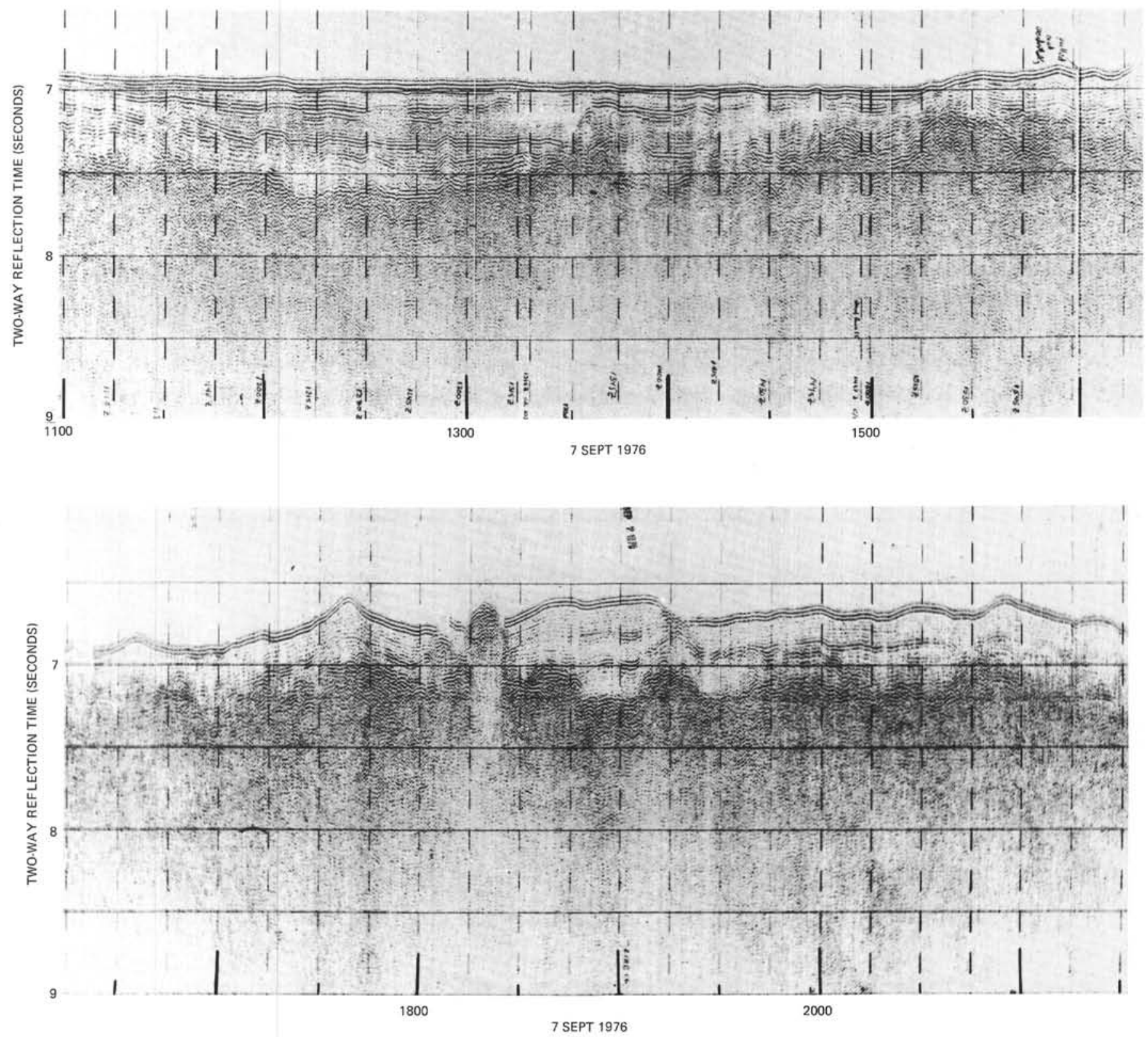

Figure 4. (Continued). 

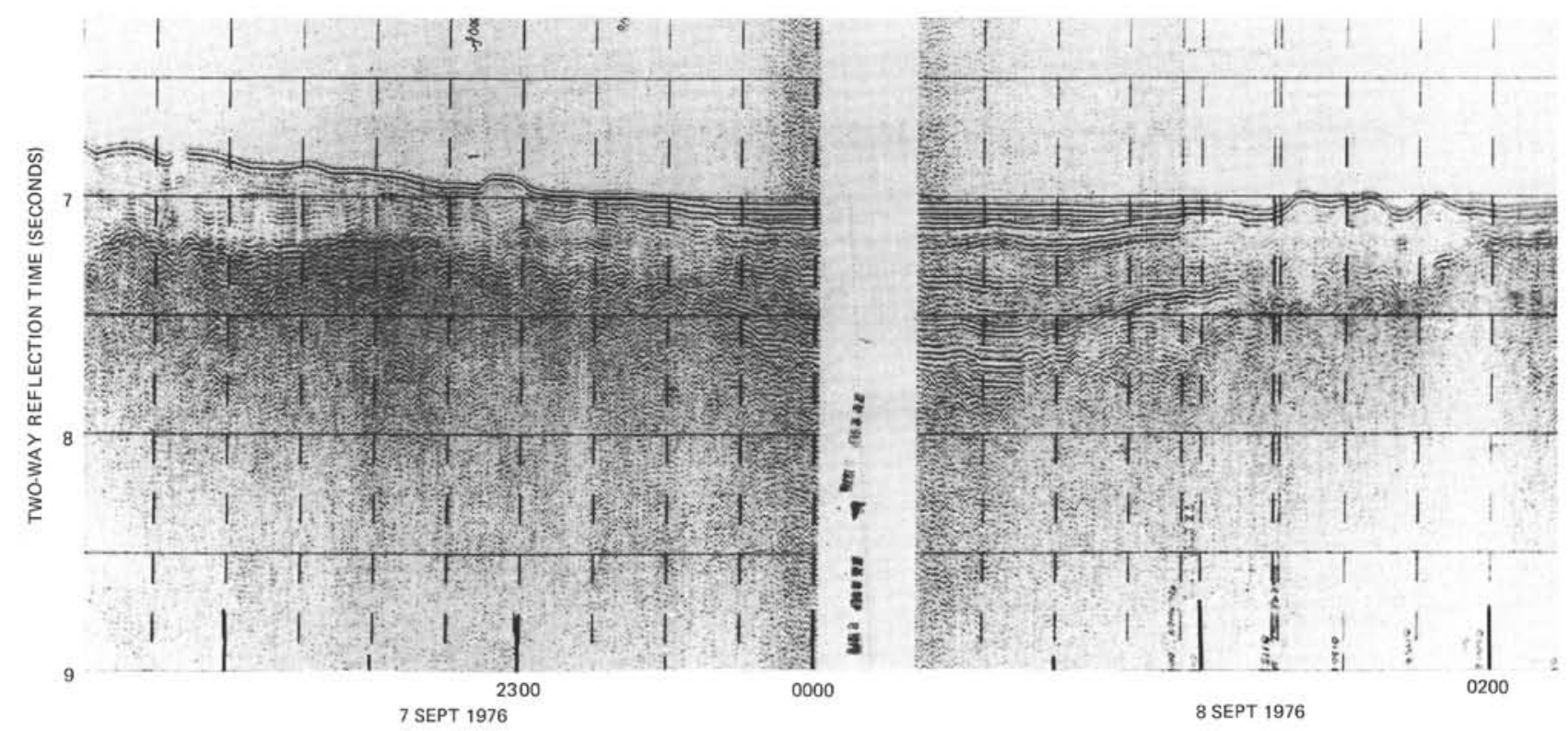

Figure 4. (Continued). 


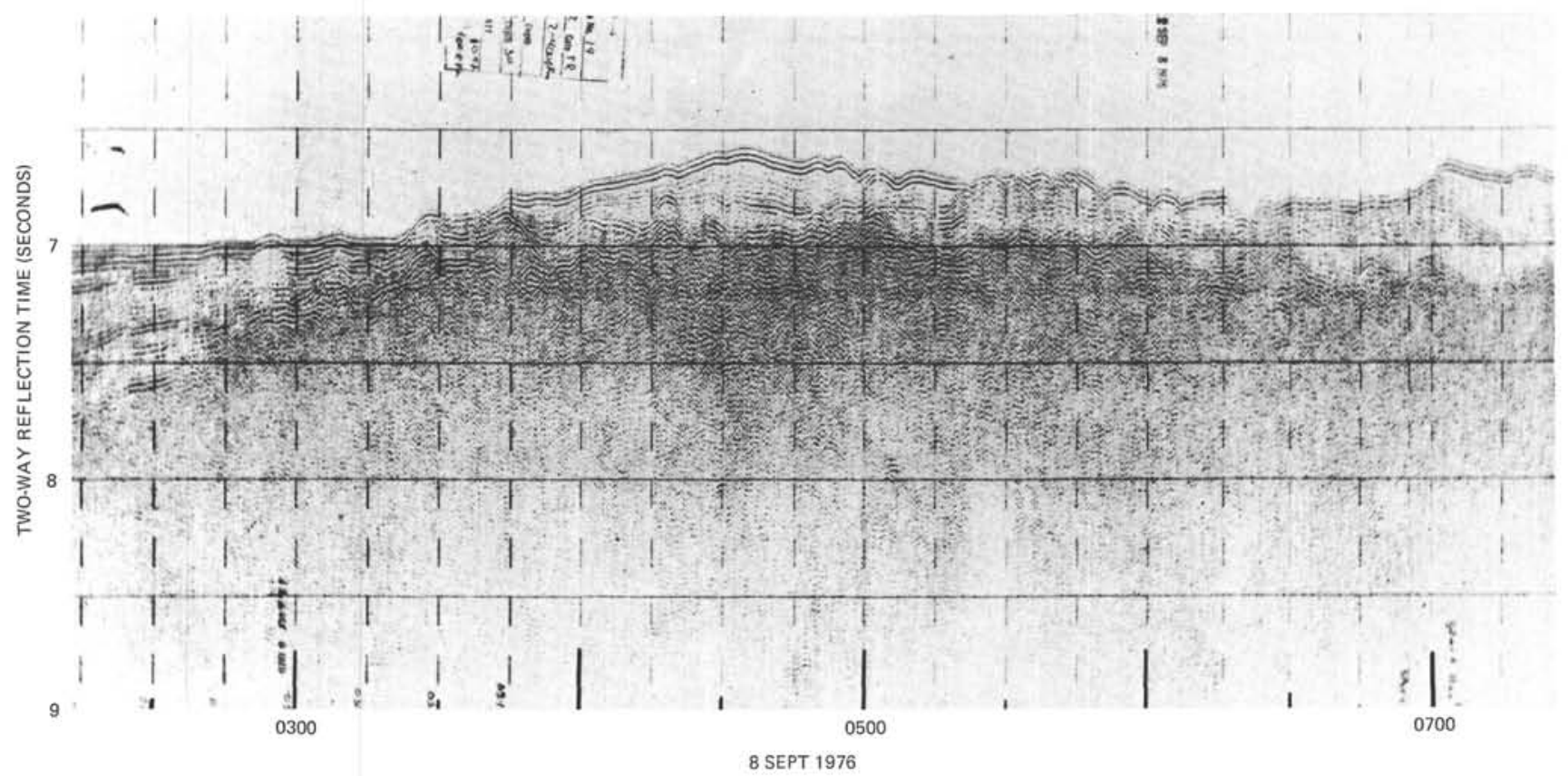

Figure 4. (Continued). 


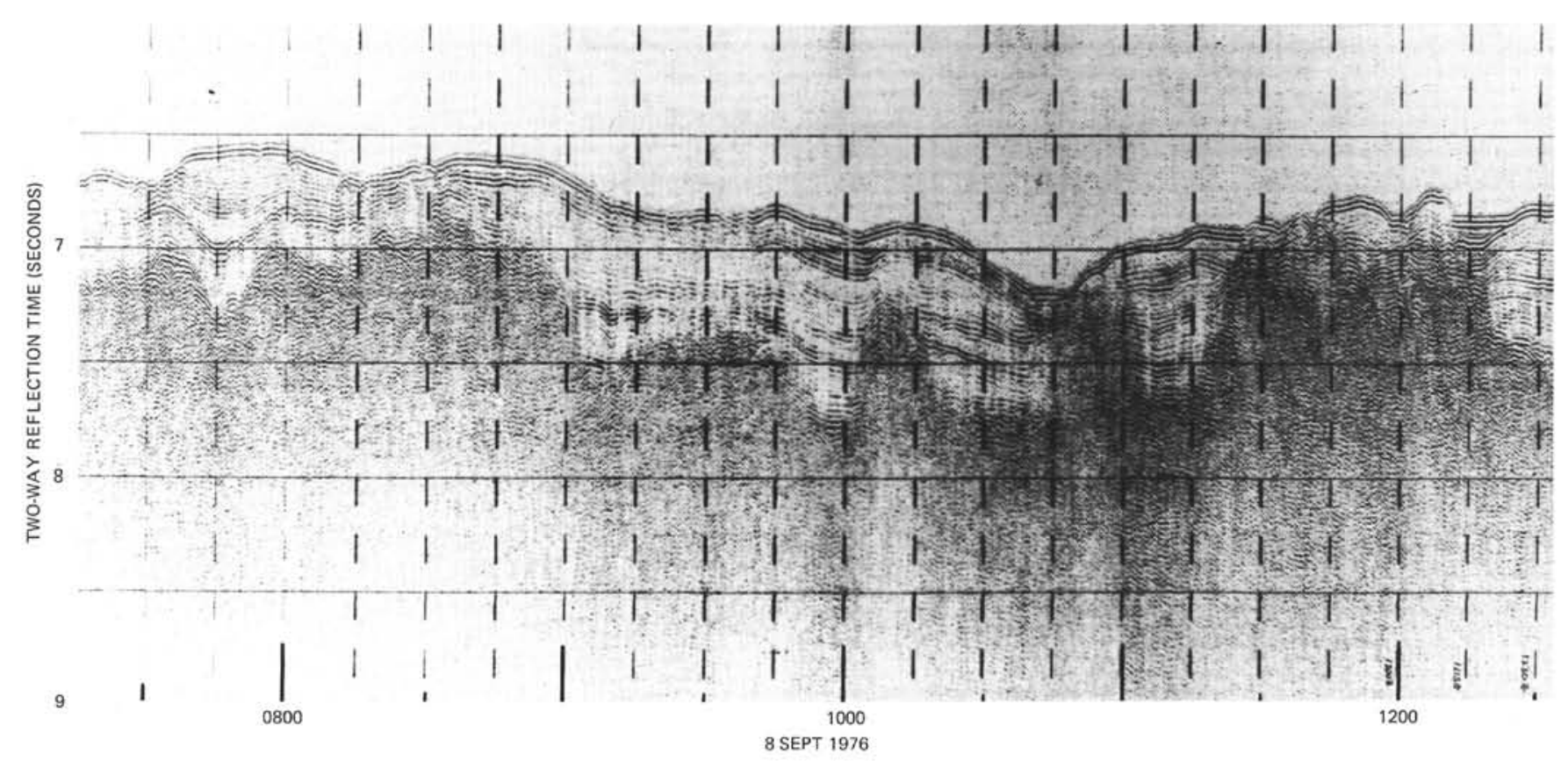

Figure 4. (Continued). 

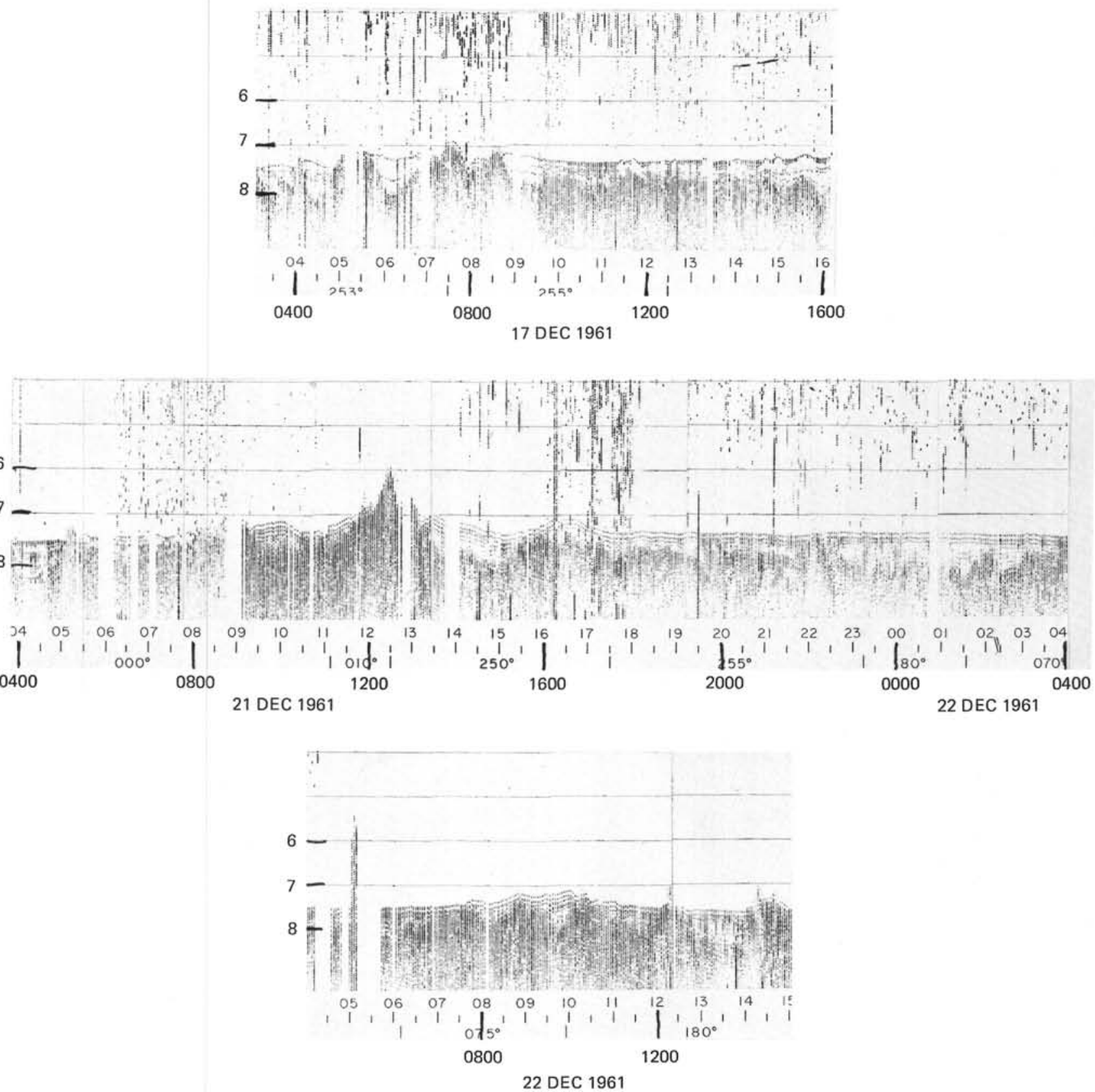

Figure 5. Seismic reflection profiler records collected aboard $R$. V. Vema, Cruise 1802. Vertical scale in seconds of two-way reflection time. Horizontal scale given in time along ships' tracks and is keyed to Figure 1. Explosives fired at two to three-min intervals used as sound source. 


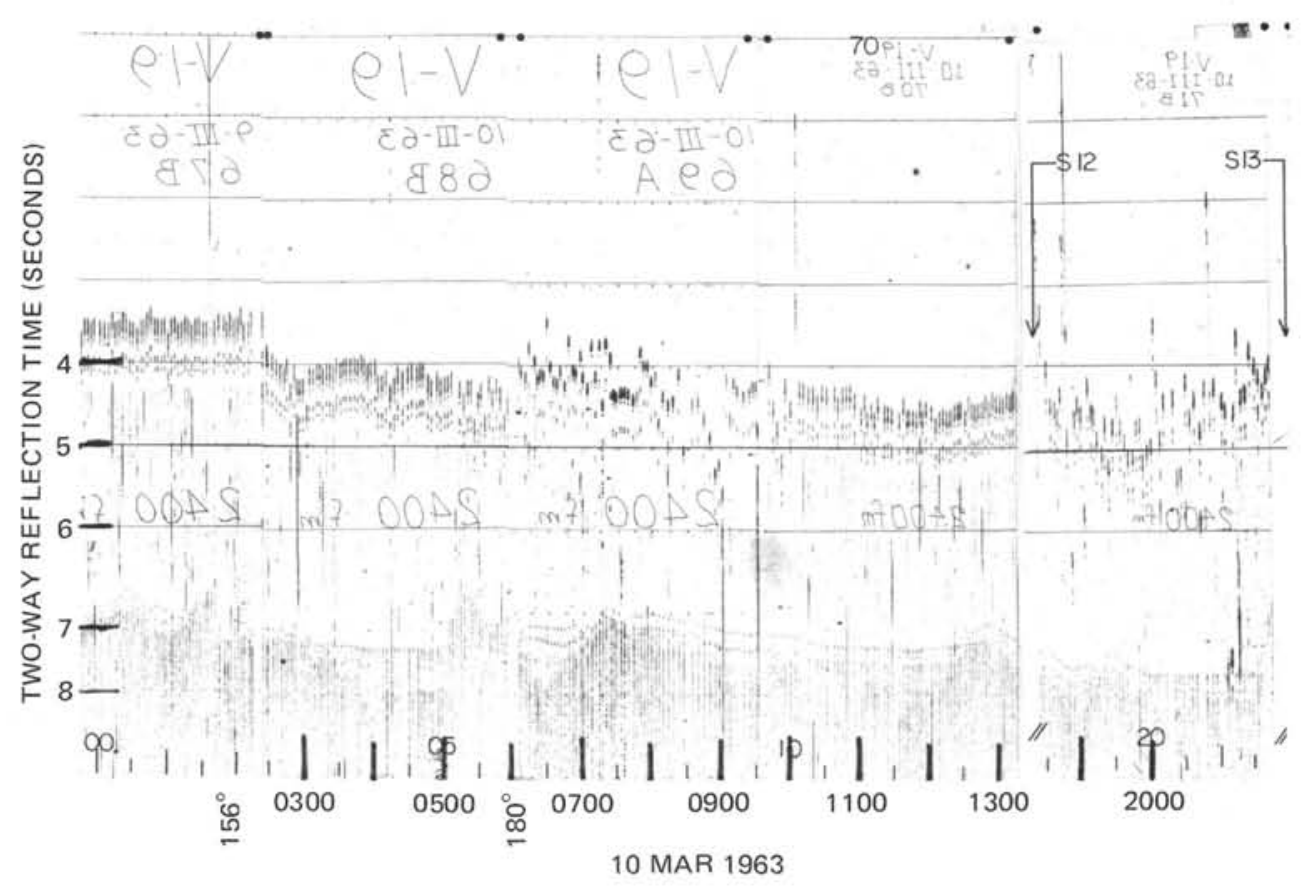

Figure 6. Seismic reflection profiler records collected aboard $R$. V. Vema, Cruise 1902. Vertical scale in seconds of two-way reflection time. Horizontal scale given in time along ships' tracks and is keyed to Figure 1. Explosives fired at two to three-min intervals used as sound source. 


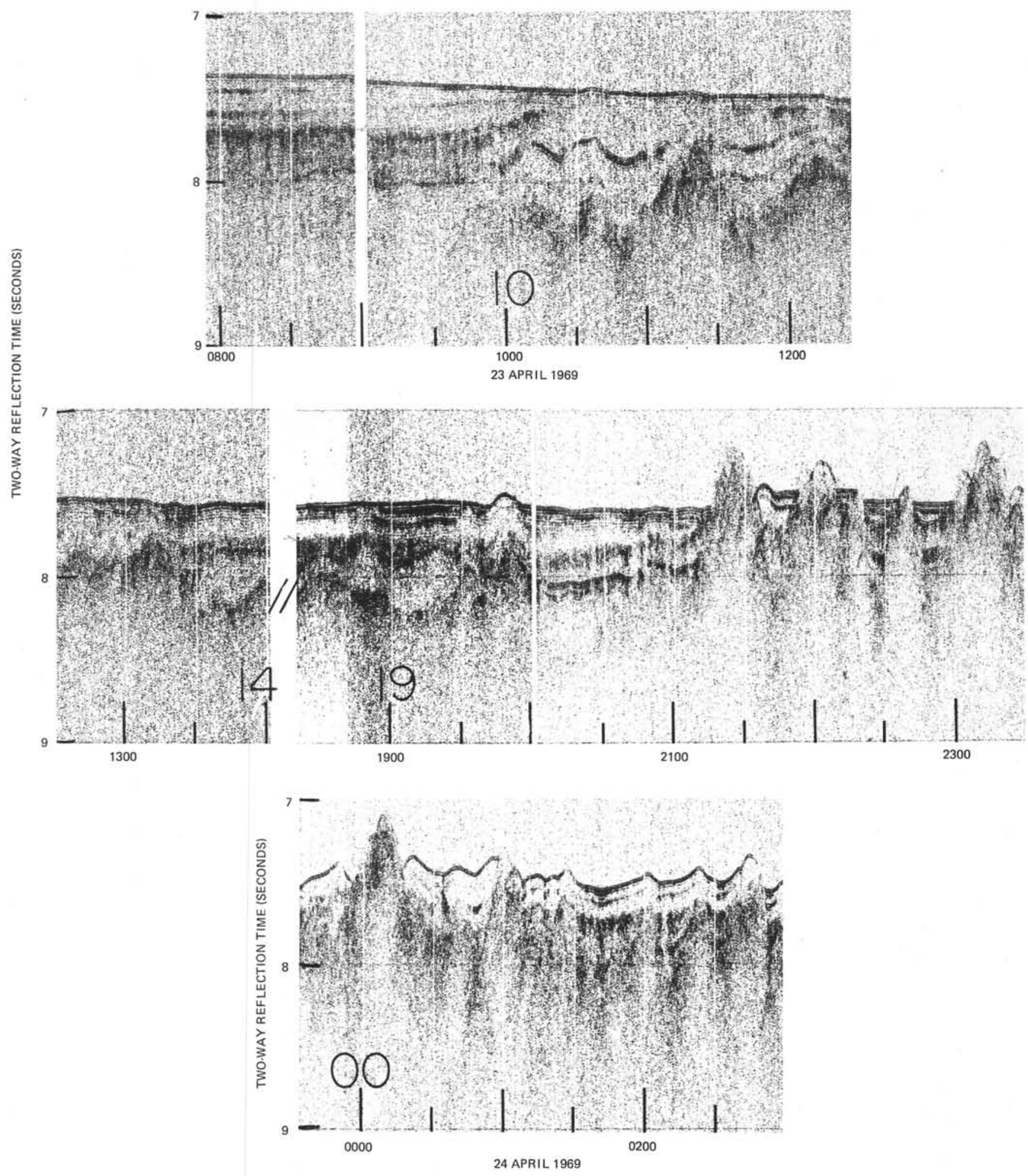

Figure 7. (a, b) Seismic reflection profiler records collected aboard R. V. Vema, Cruise 2609. Vertical scale in seconds of two-way reflection time. Horizontal scale given in time along ships' tracks and is keyed to Figure 1. Free-firing airgun with repetition rate of $\sim 12 \mathrm{~s}$ used as sound source. 


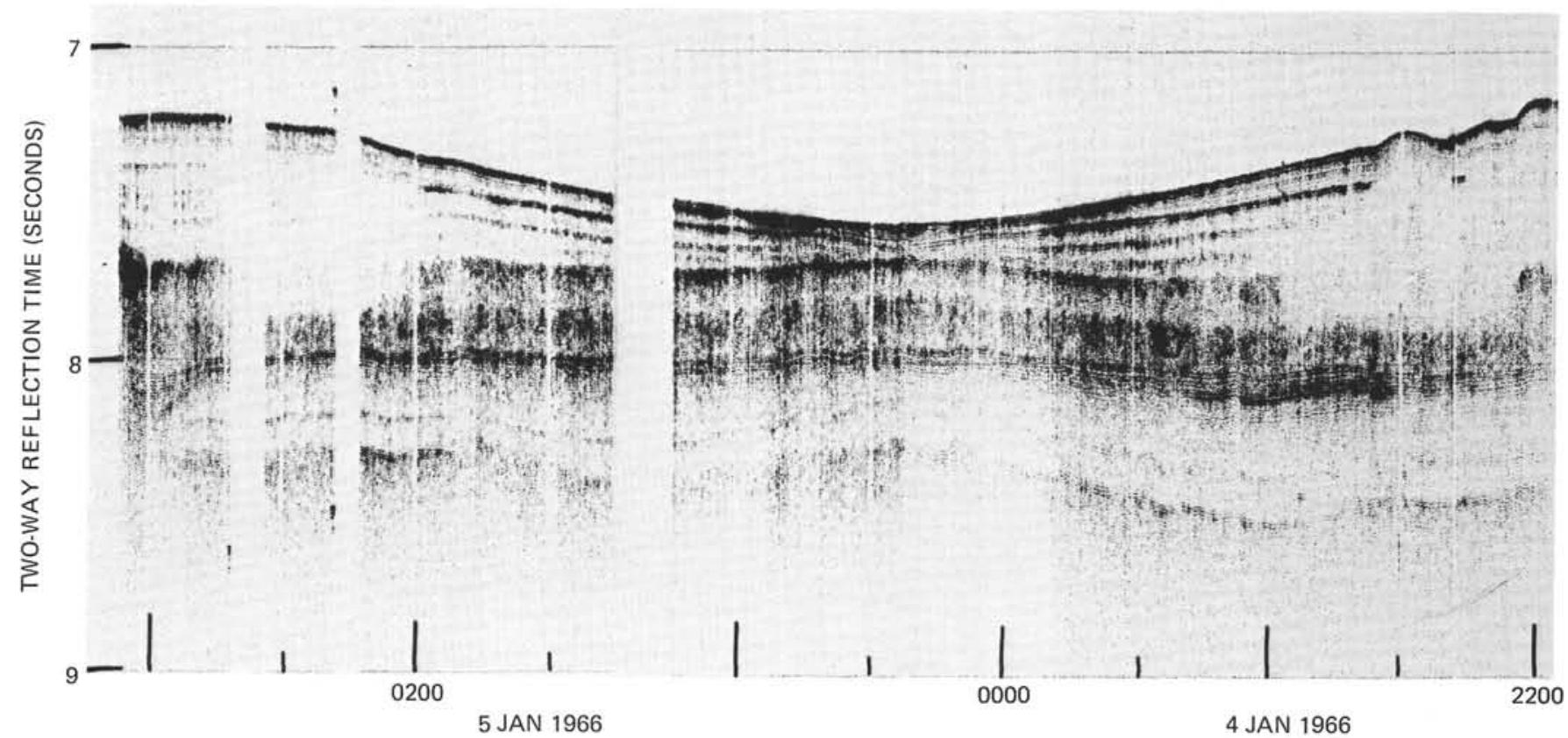

Figure 8. Seismic reflection profiler records collected aboard $R$. V. Robert D. Conrad, Cruise 1003. Vertical scale in seconds of. two-way reflection time. Horizontal scale given in time along ships' tracks and is keyed to Figure 1. Free-firing airgun with repetition rate of $\sim 12 \mathrm{~s}$ used as sound source. 


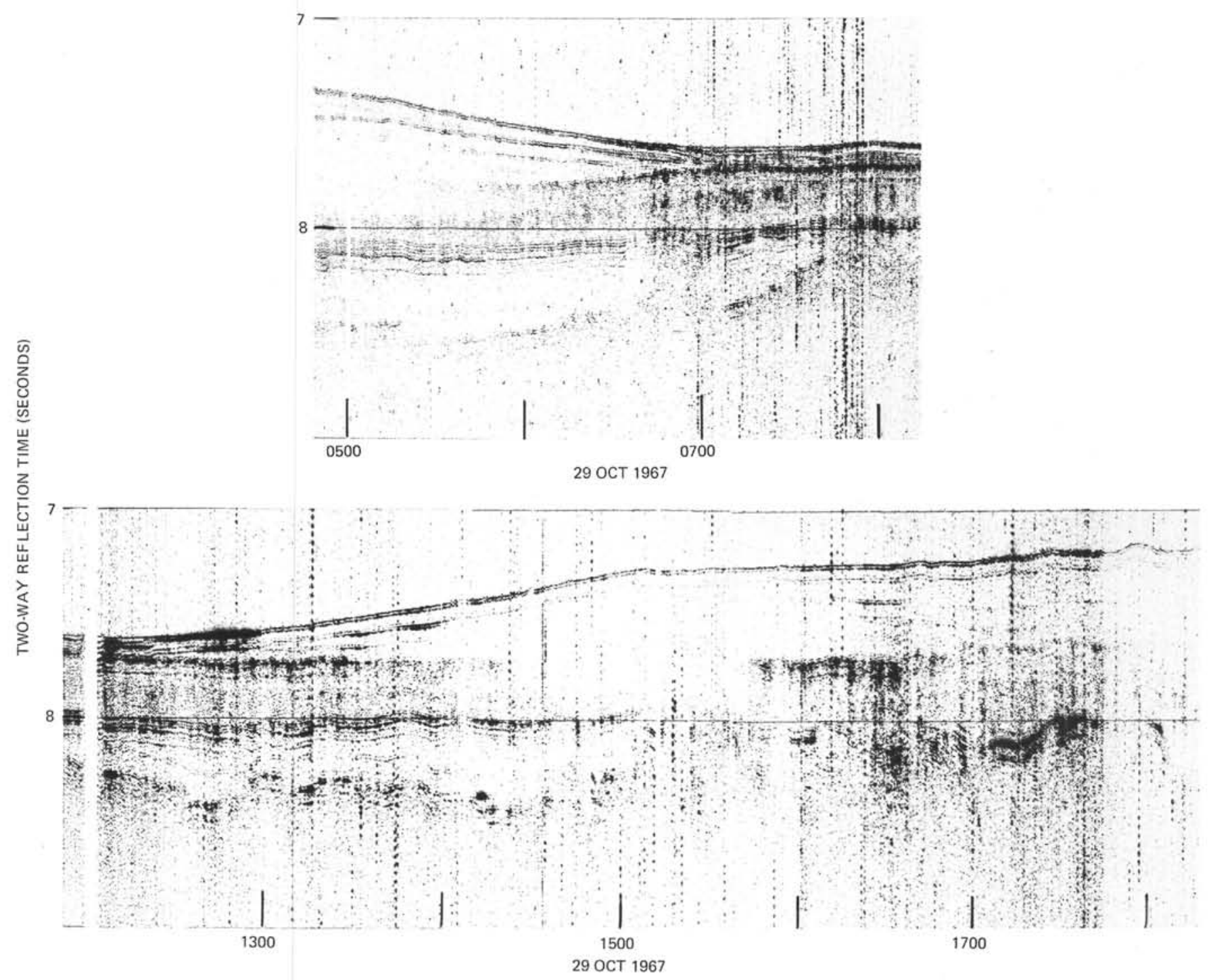

Figure 9. Seismic reflection profiler records collected aboard R. V. Robert D. Conrad, Cruise 1112. Vertical scale in seconds of two-way reflection time. Horizontal scale given in time along ships' tracks and is keyed to Figure 1. Free-firing airgun with repetition rate of $\sim 12 \mathrm{~s}$ used as sound source. 


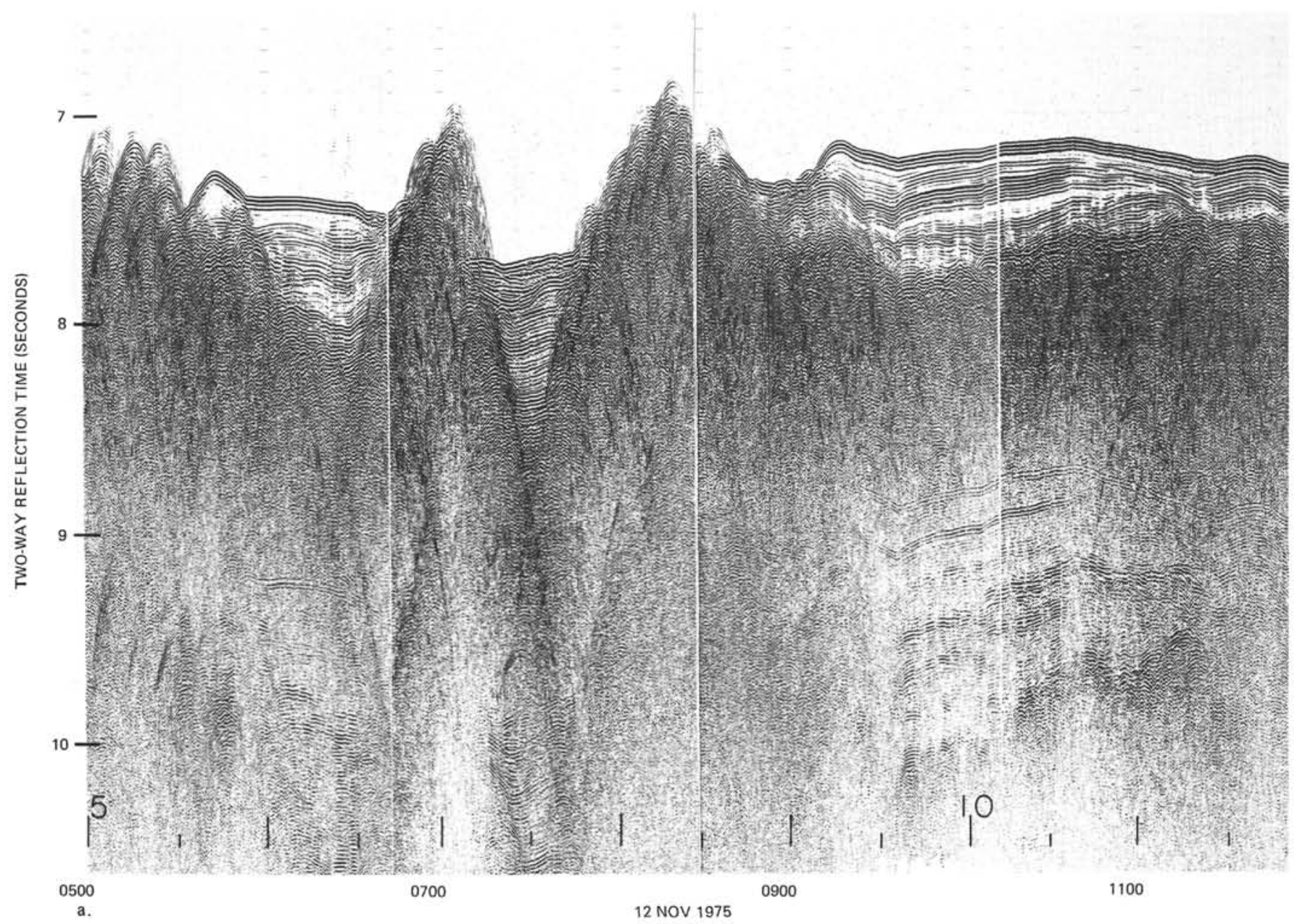

Figure 10 (a-c). Seismic reflection profiler records collected aboard R. V. Robert D. Conrad, Cruise 1903. Vertical scale in seconds of two-way reflection time. Horizontal scale given in time along ships' tracks and is keyed to Figure 1. Free-firing airgun with repetition rate of $\sim 12 \mathrm{~s}$ used as sound source. 


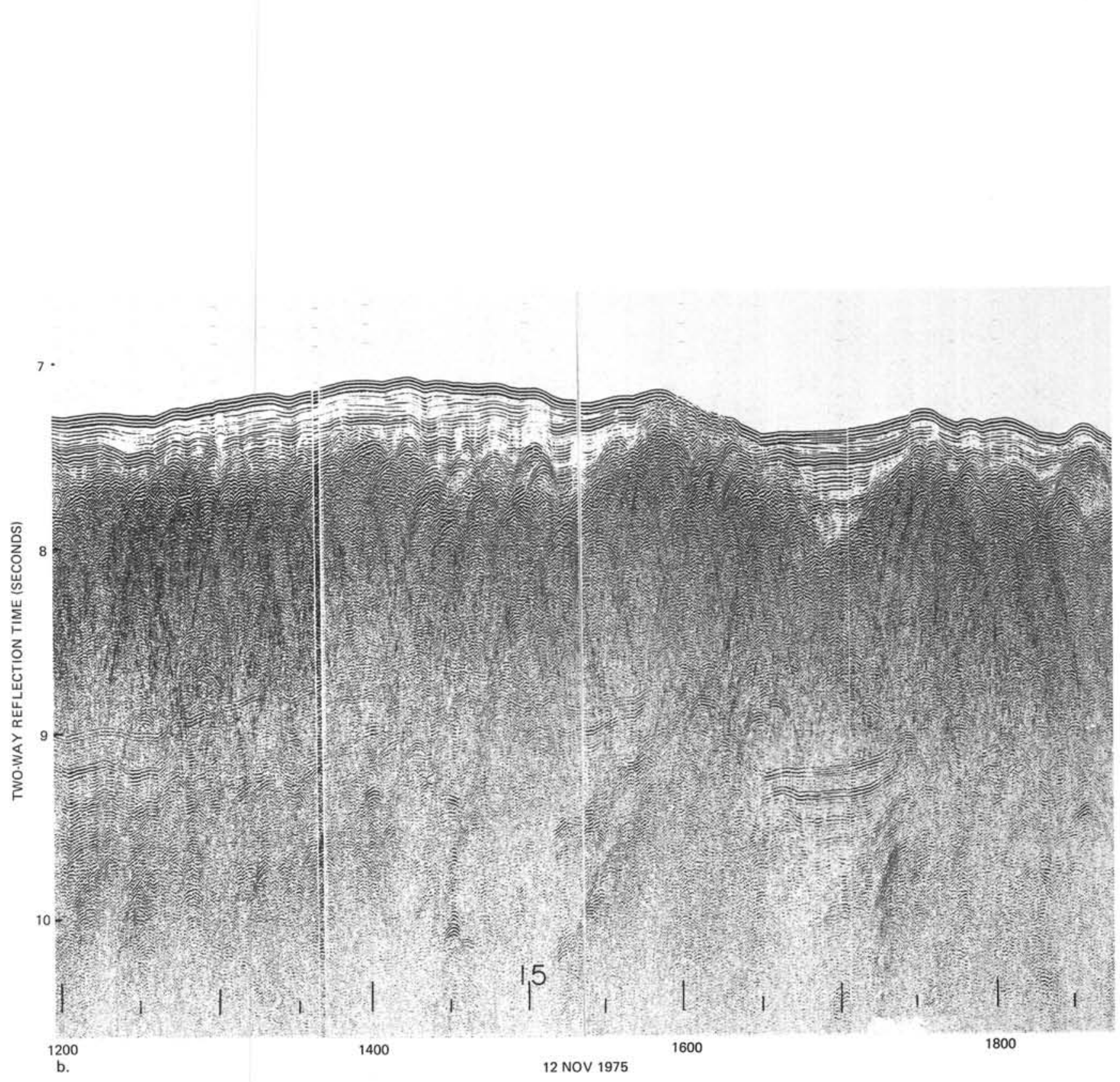

Figure 10. (Continued). 


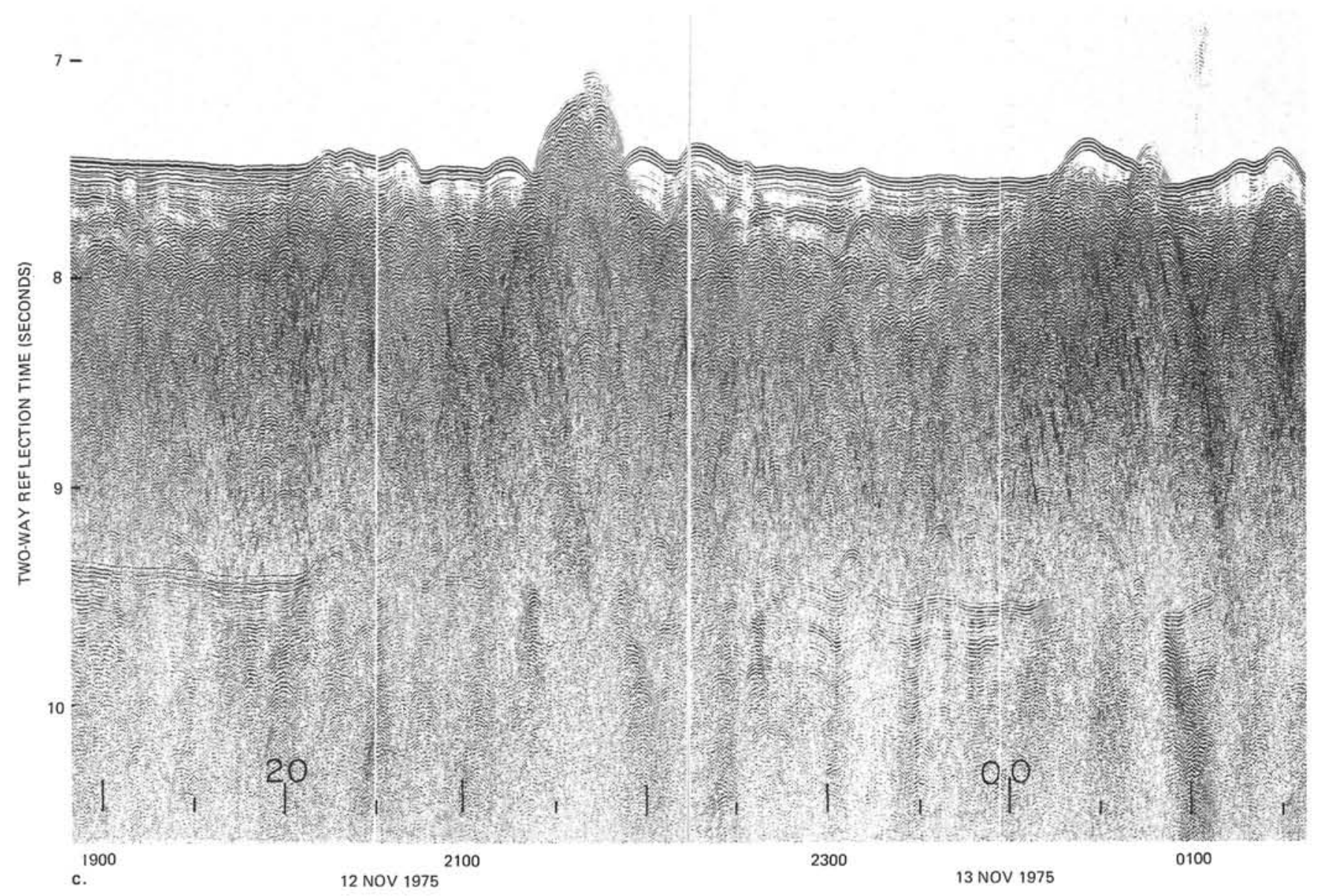

Figure 10. (Continued). 


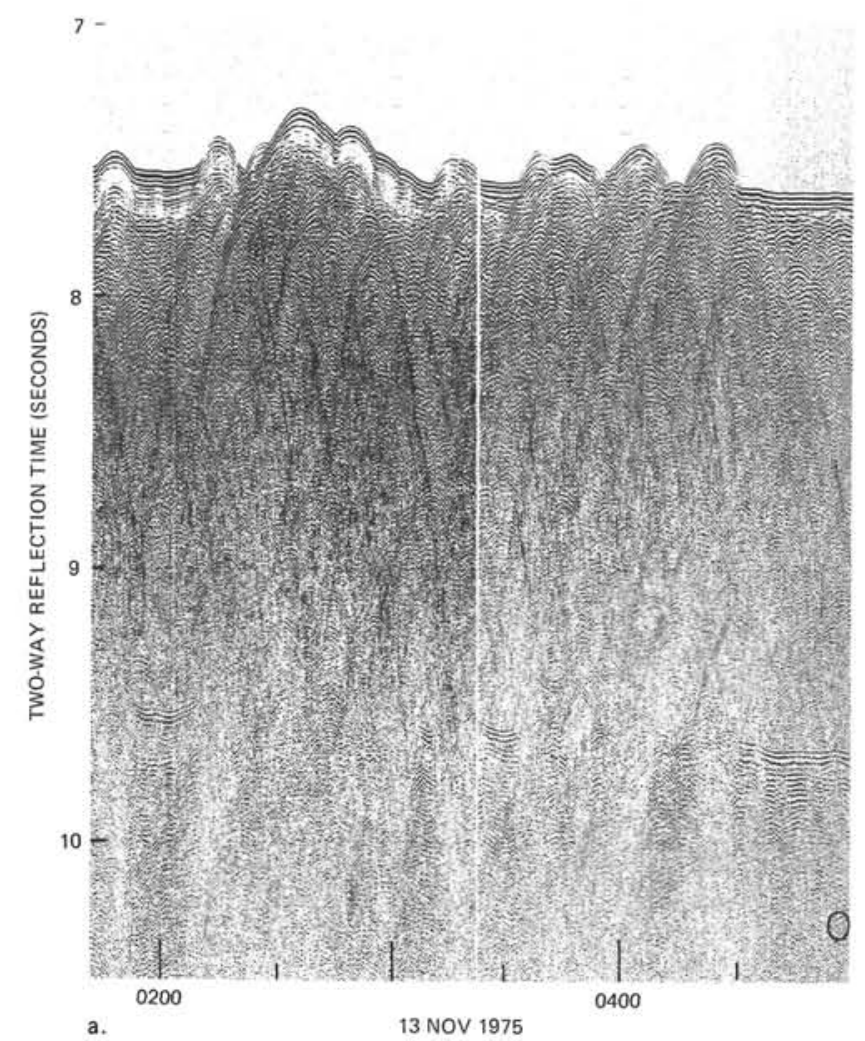

Figure $11(\mathrm{a}, \mathrm{b})$. Seismic reflection profiler records collected aboard R. V. Robert D. Conrad, Cruise 1904. Vertical scale in seconds of two-way reflection time. Horizontal scale given in time along ships' tracks and is keyed to Figure 1. Free-firing airgun with repetition rate of $\sim 12 \mathrm{~s}$ used as sound source. 


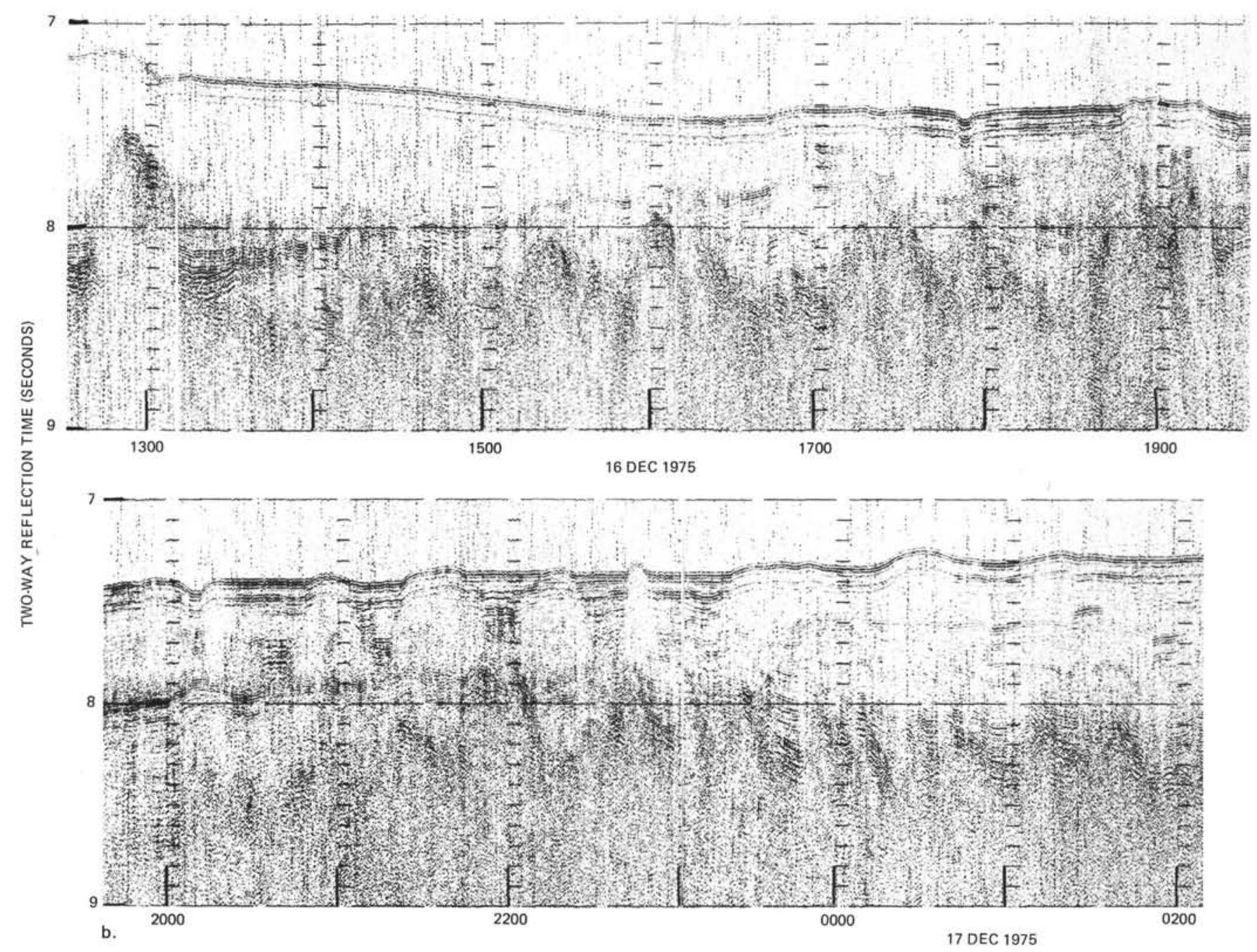

Figure 11. (Continued). 


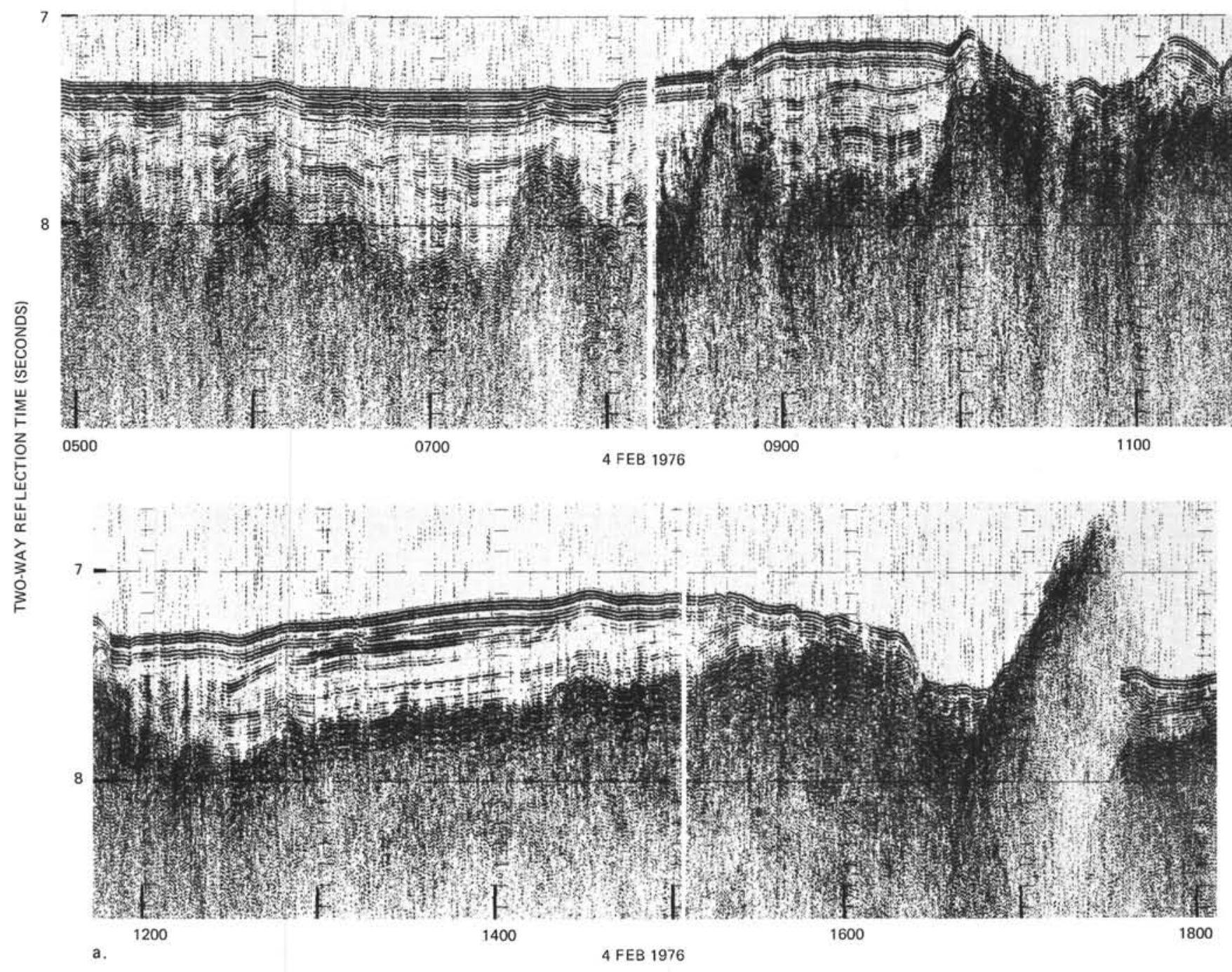

Figure 12 (a,b). Seismic reflection profiler records collected aboard $R$. V. Robert D. Conrad, Cruise 1906. Vertical scale in seconds of two-way reflection time. Horizontal scale given in time along ships' tracks and is keyed to Figure 1. Free-firing airgun with repetition rate of $\sim 12 \mathrm{~s}$ used as sound source. 


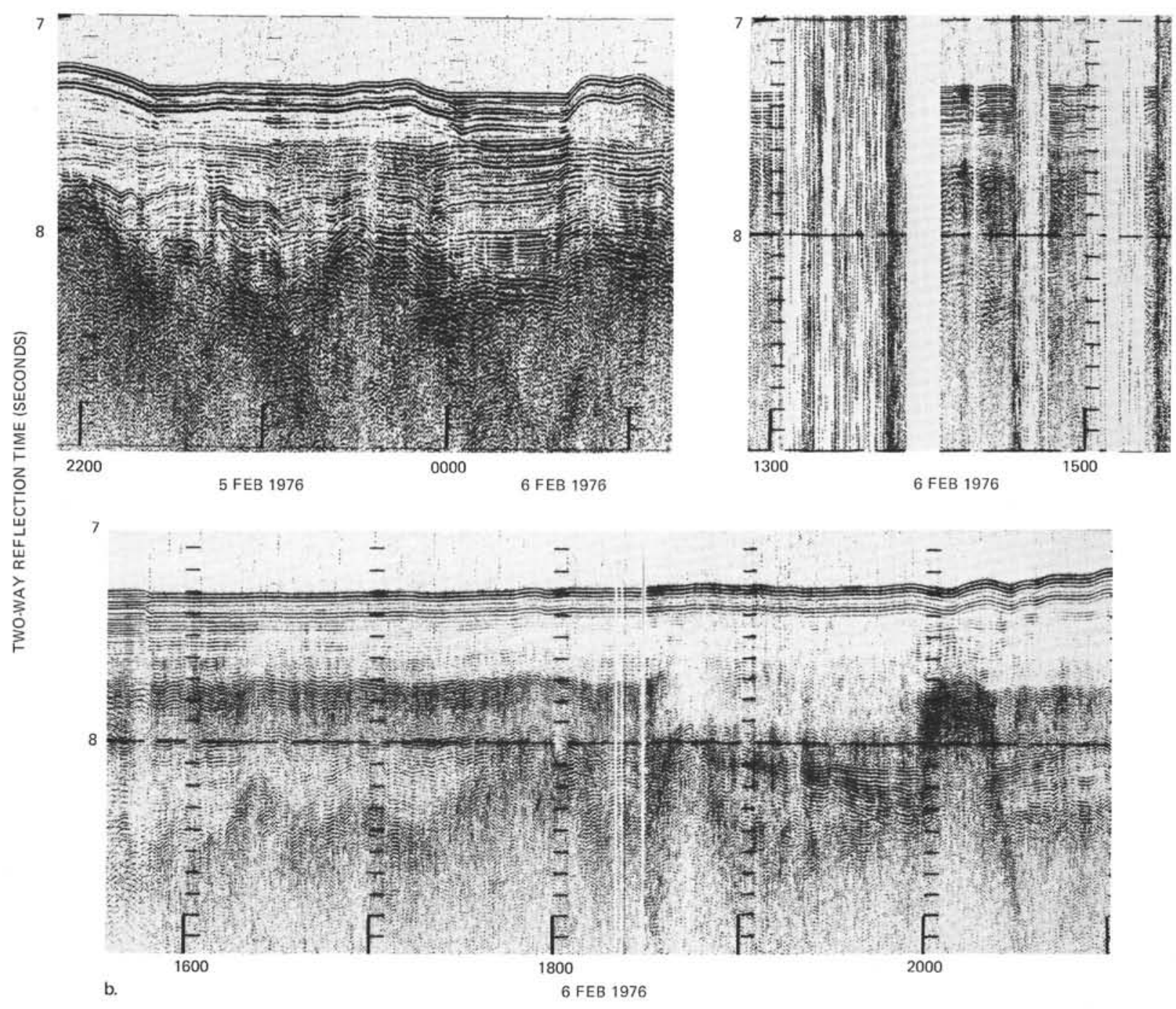

Figure 12. (Continued). 


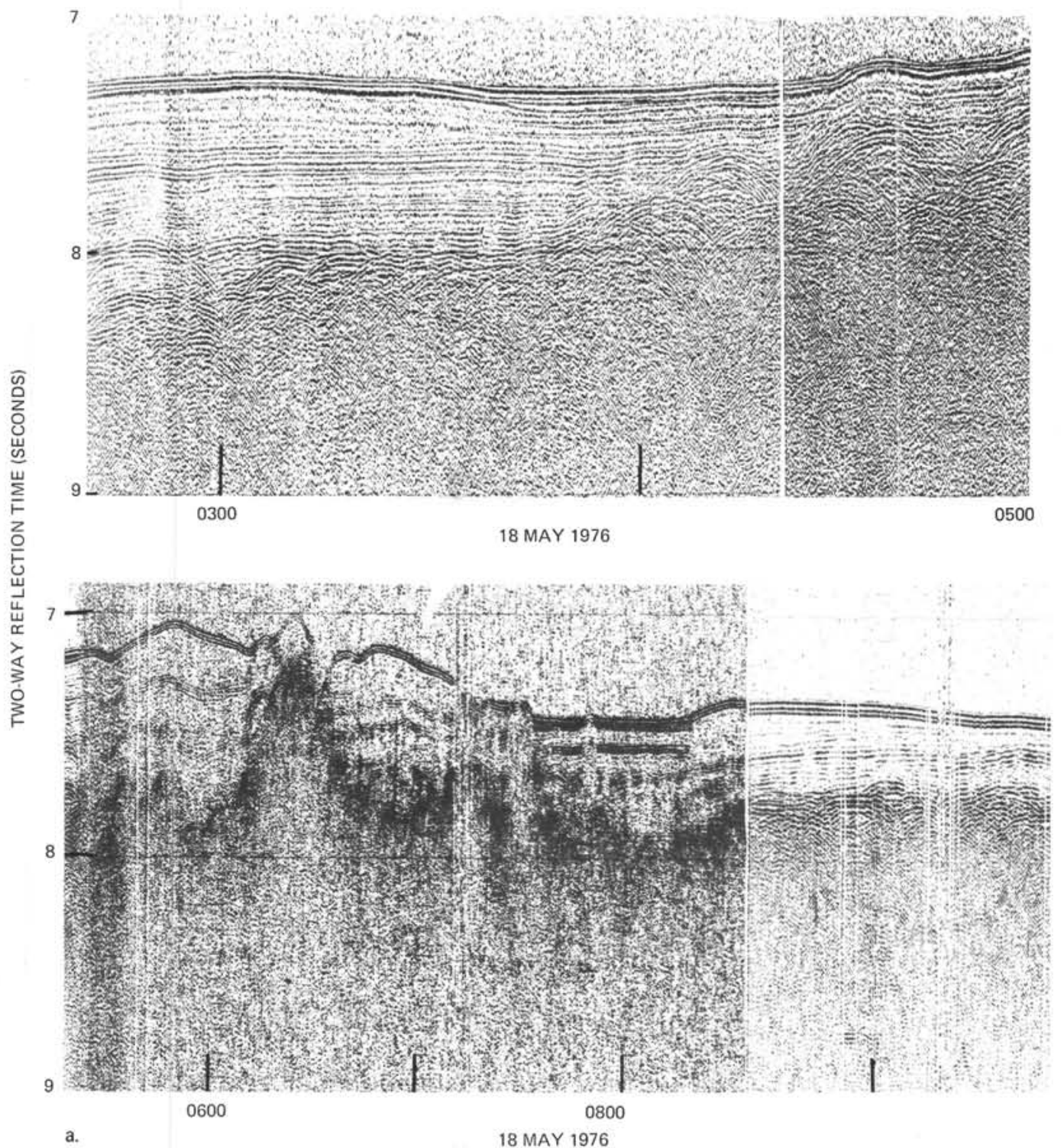

Figure 13 (a-d). Seismic reflection profiler records collected aboard $R$. V. Robert D. Conrad, Cruise 2001. Vertical scale in seconds of two-way reflection time. Horizontal scale given in time along ships' tracks and is keyed to Figure 1. Free-firing airgun with repetition rate of $\sim 12 \mathrm{~s}$ used as sound source. 


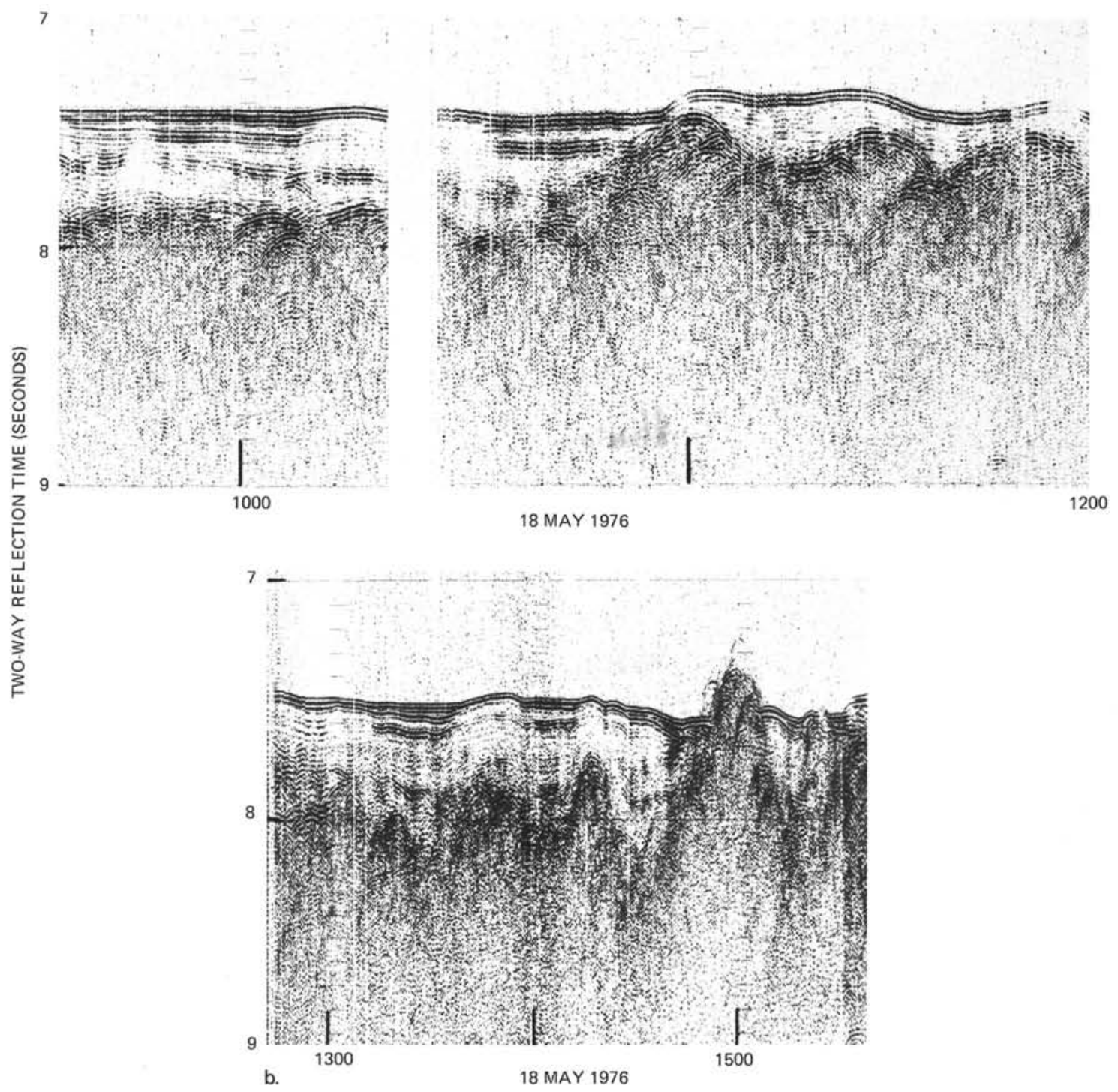

Figure 13. (Continued). 


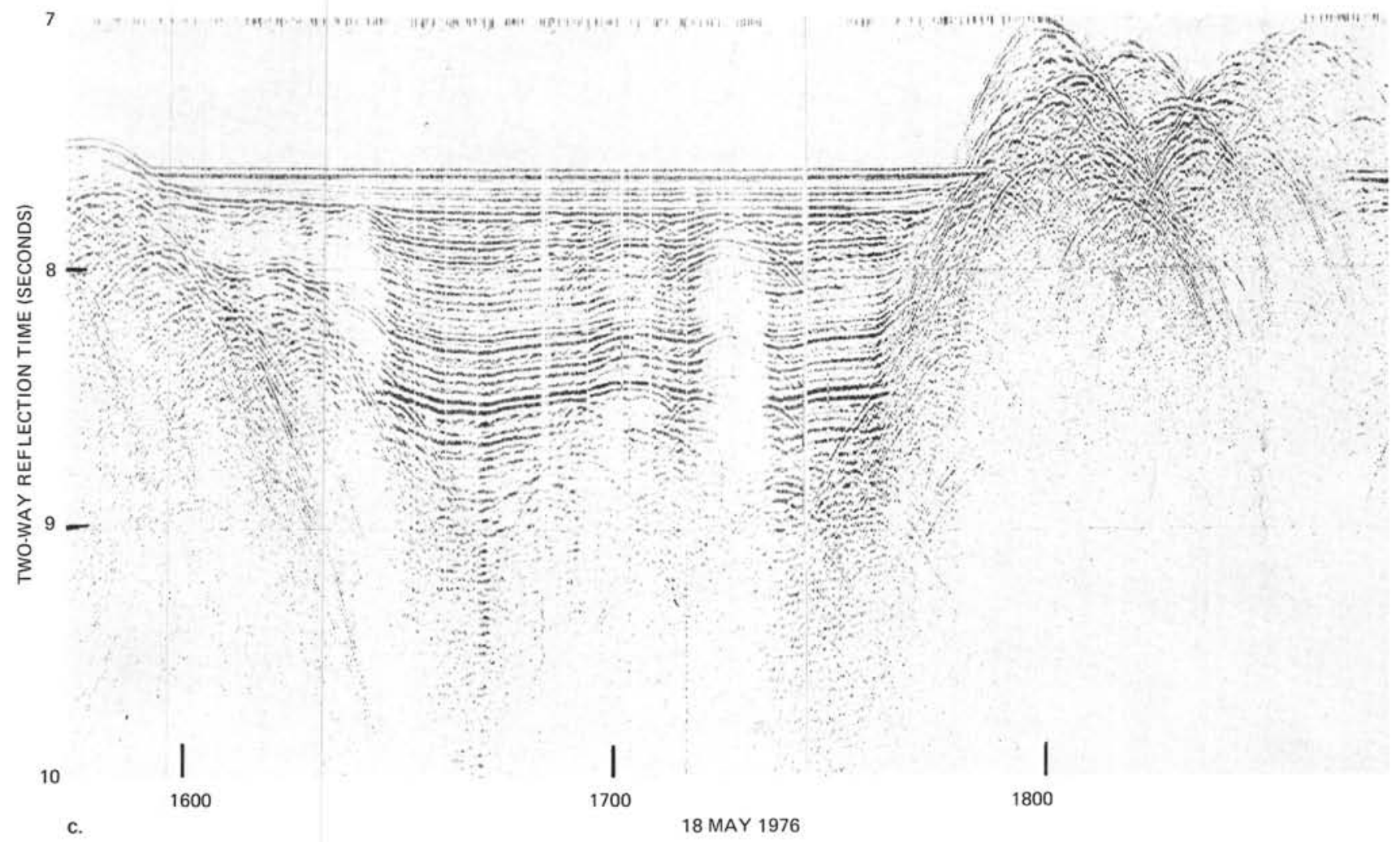

Figure 13. (Continued). 

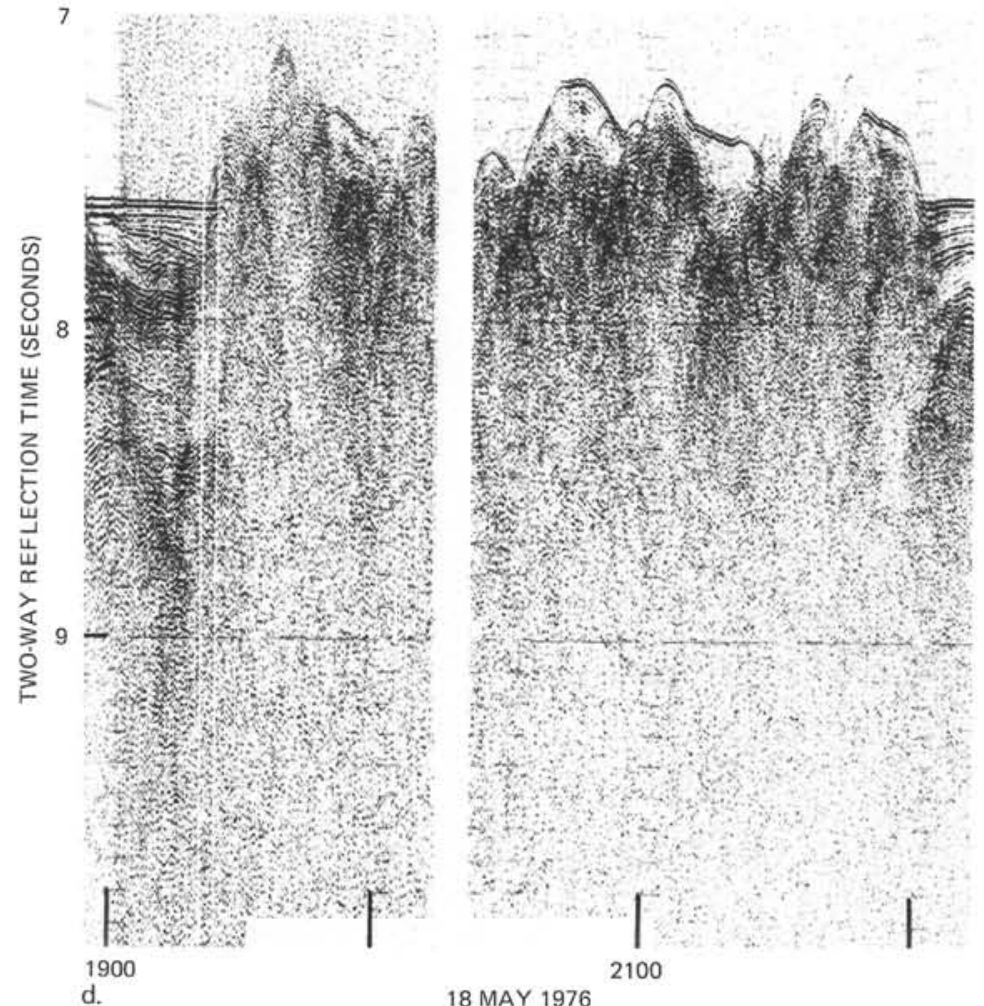

Figure 13. (Continued). 

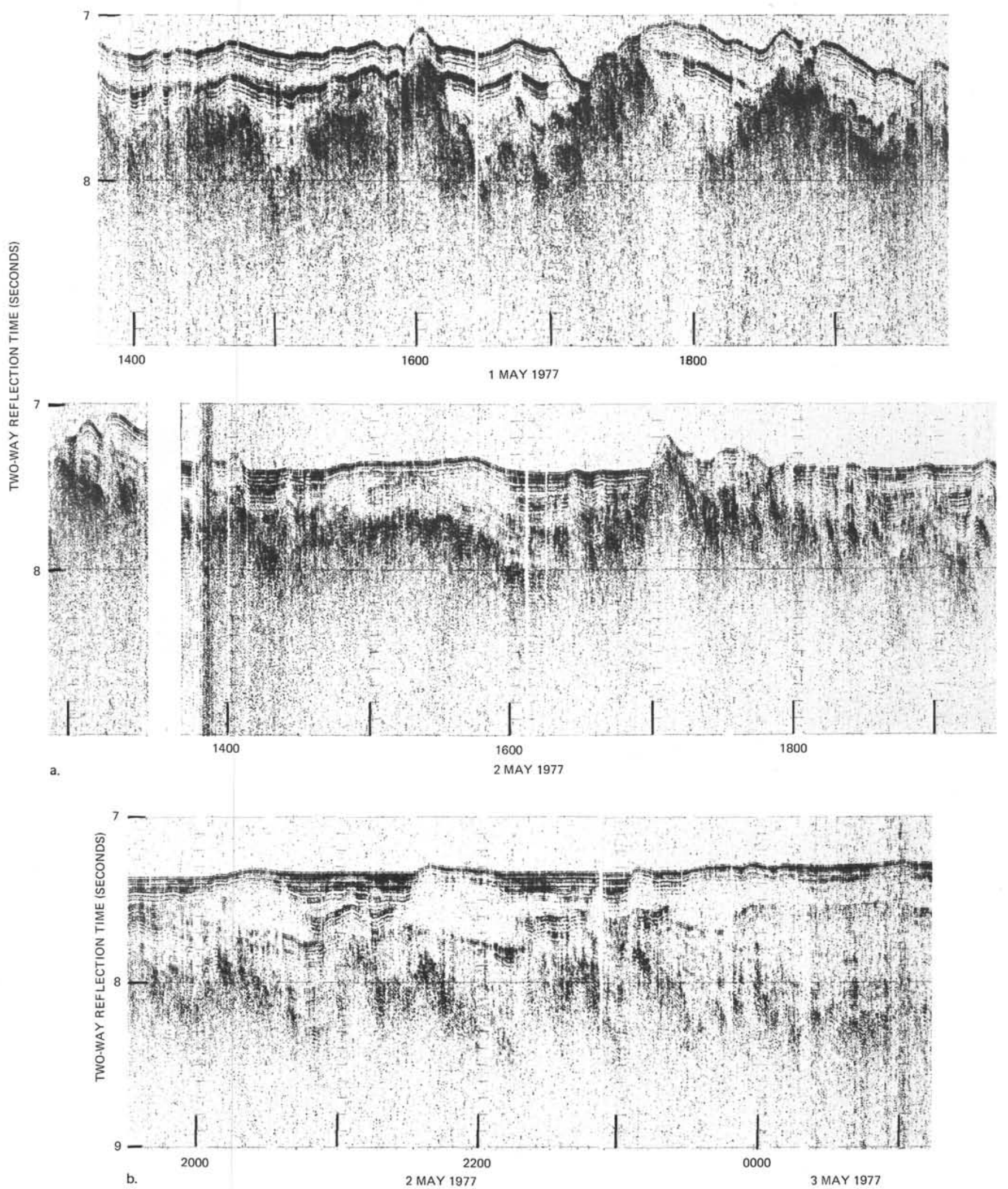

Figure 14. (a,b) Seismic reflection profiler records collected aboard R. V. Robert D. Conrad, Cruise 2012. Vertical scale in seconds of two-way reflection time. Horizontal scale given in time along ships' tracks and is keyed to Figure 1. Free-firing airgun with repetition rate of $\sim 12 \mathrm{~s}$ used as sound source. 


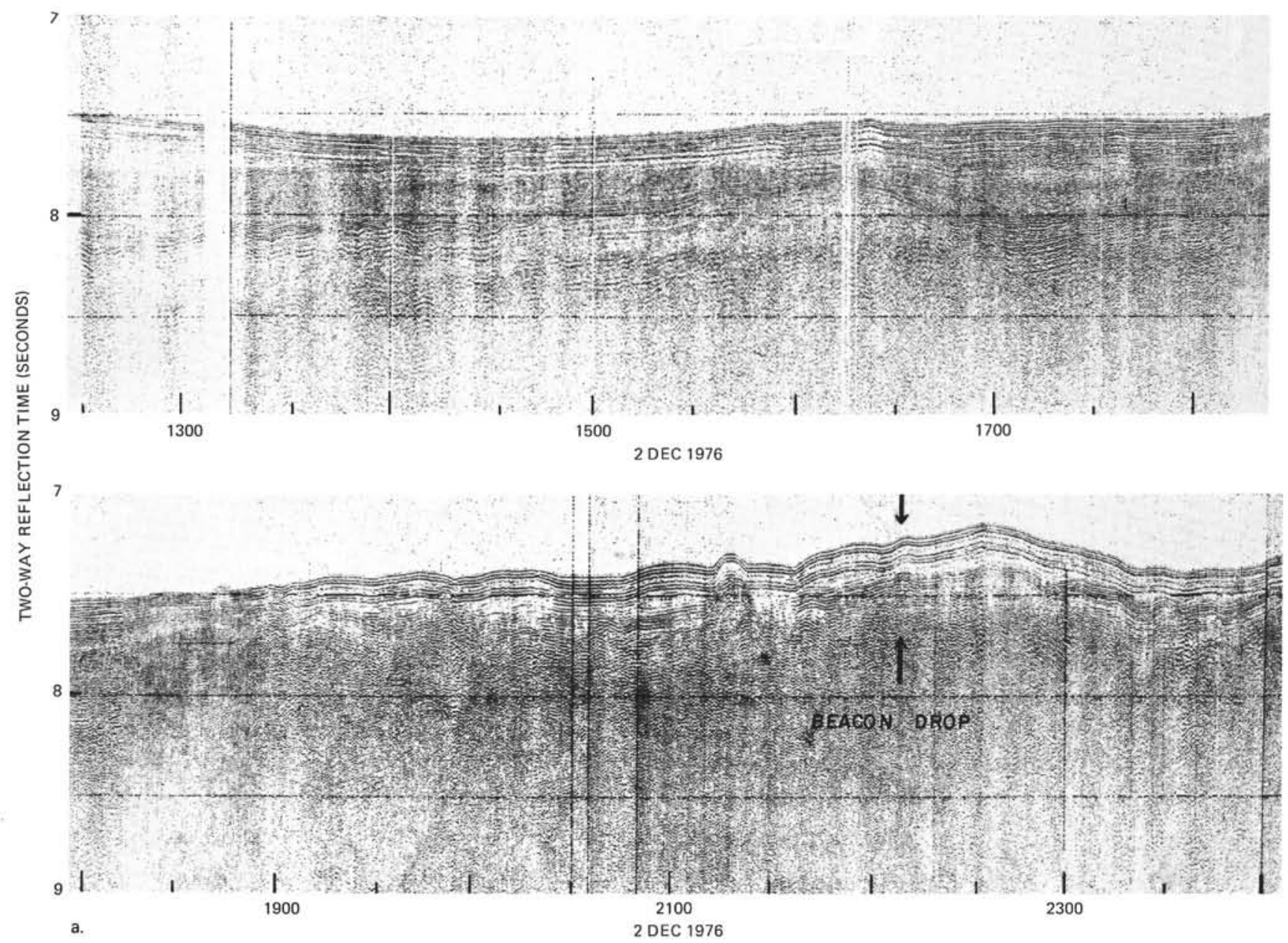

Figure 15 (a,b). Seismic reflection profiler records collected aboard D. V. Glomar Challenger, Leg 51A. Vertical scale in seconds of two-way reflection time. Horizontal scale given in time along ships' tracks and is keyed to Figure 1. Airgun with repetition rate of $10 \mathrm{~s}$ used as sound source. 


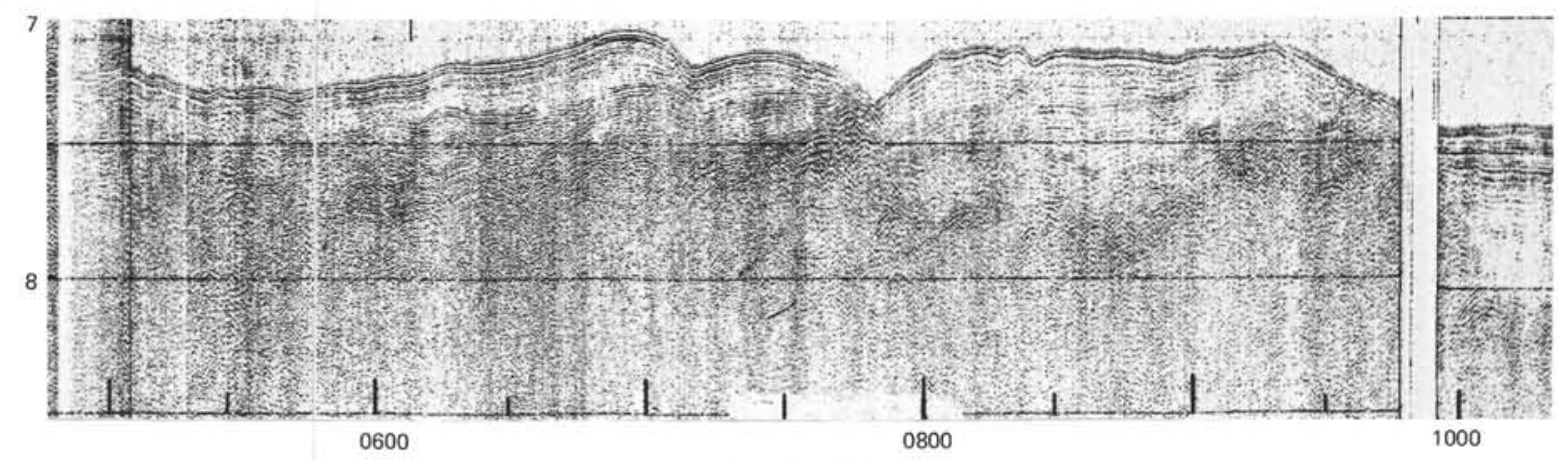

11 DEC 1976
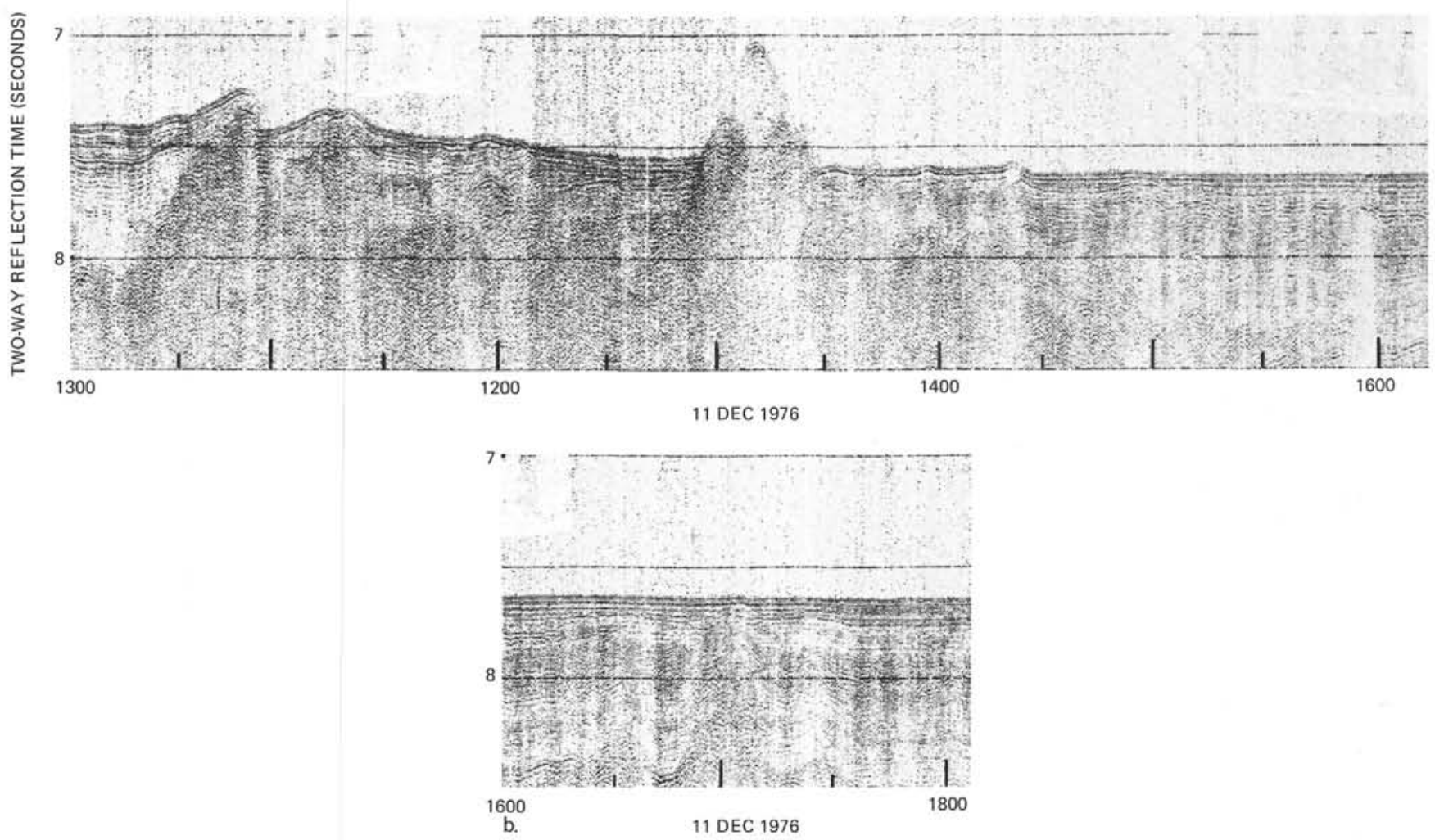

Figure 15. (Continued). 


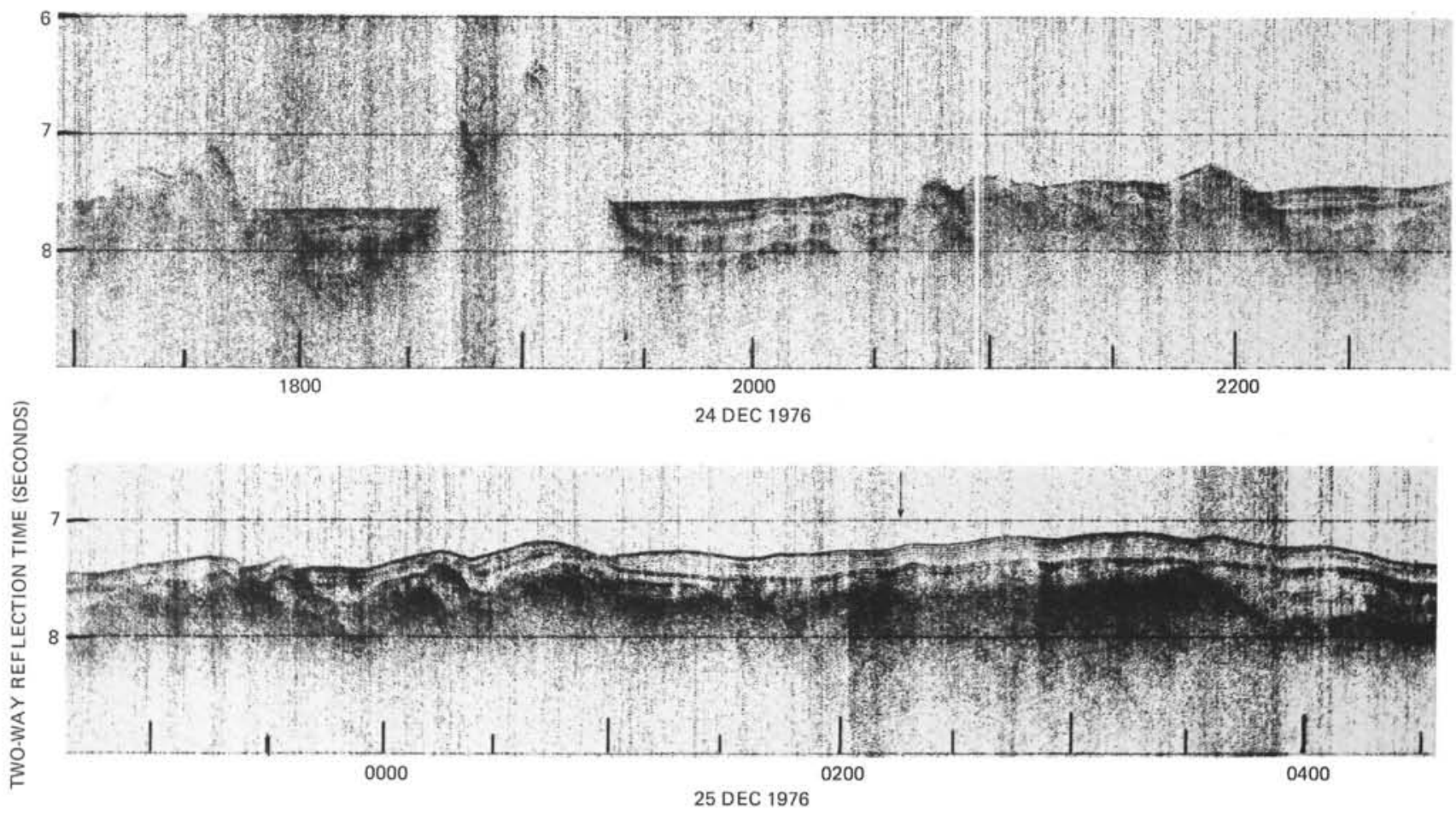

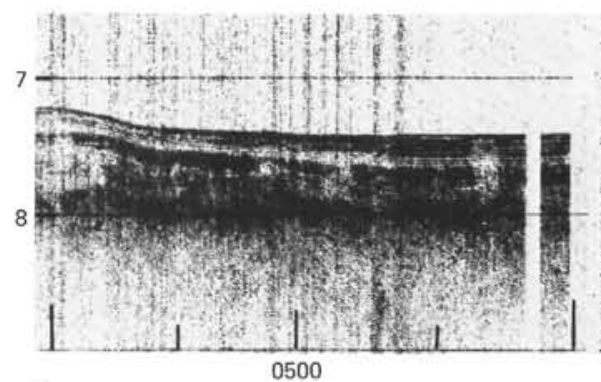

a.

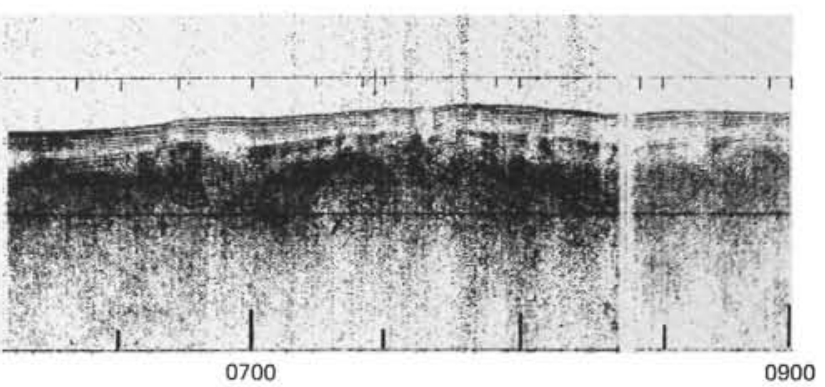

25 DEC 1976

Figure 16 (a,b). Seismic reflection profiler records collected aboard D. V. Glomar Challenger, Leg 51B. Vertical scale in seconds of two-way reflection time. Horizontal scale given in time along ships'tracks and is keyed to Figure 1. Airgun with repetition rate of $10 \mathrm{~s}$ used as sound source. 


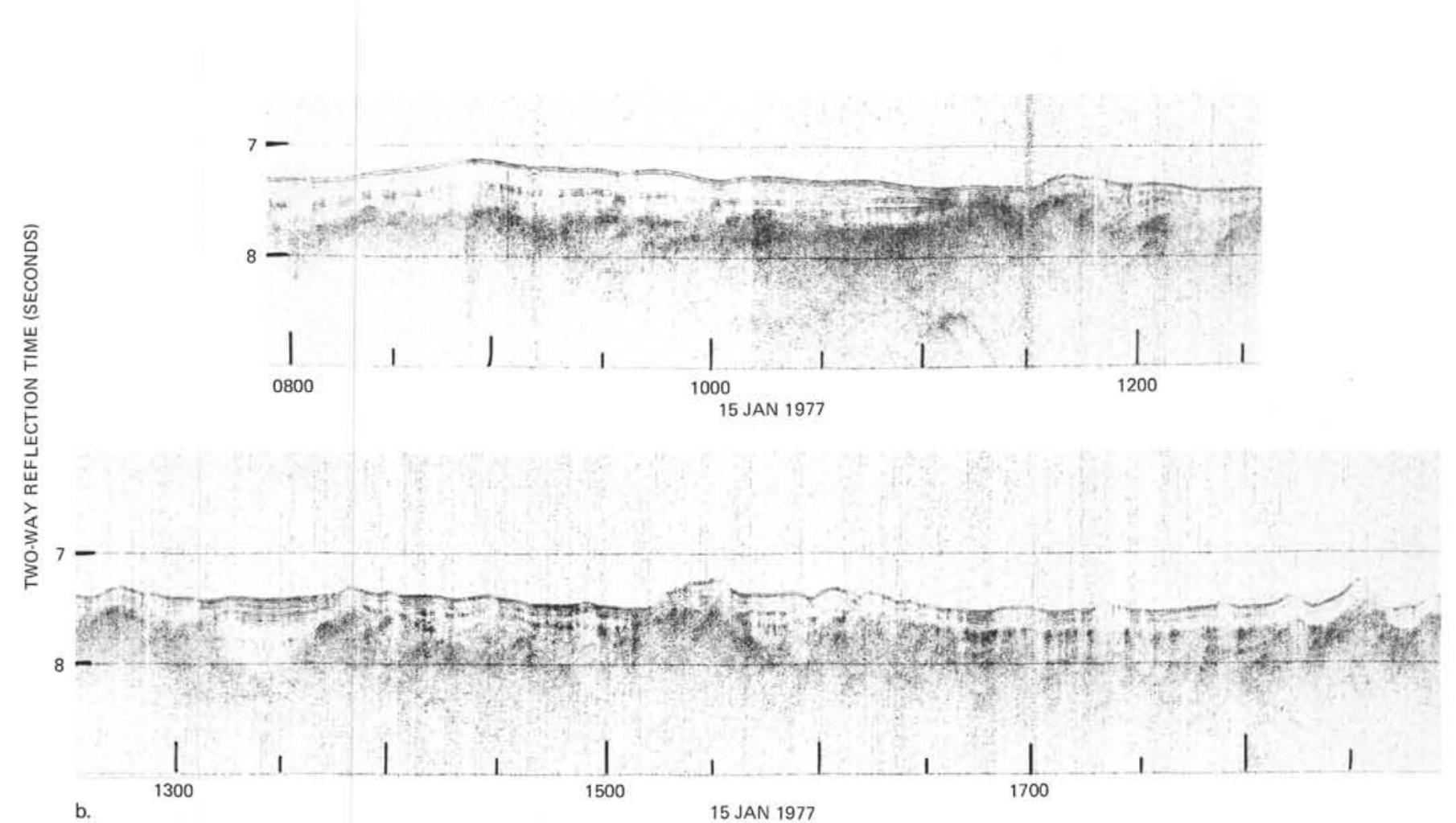

Figure 16. (Continued). 


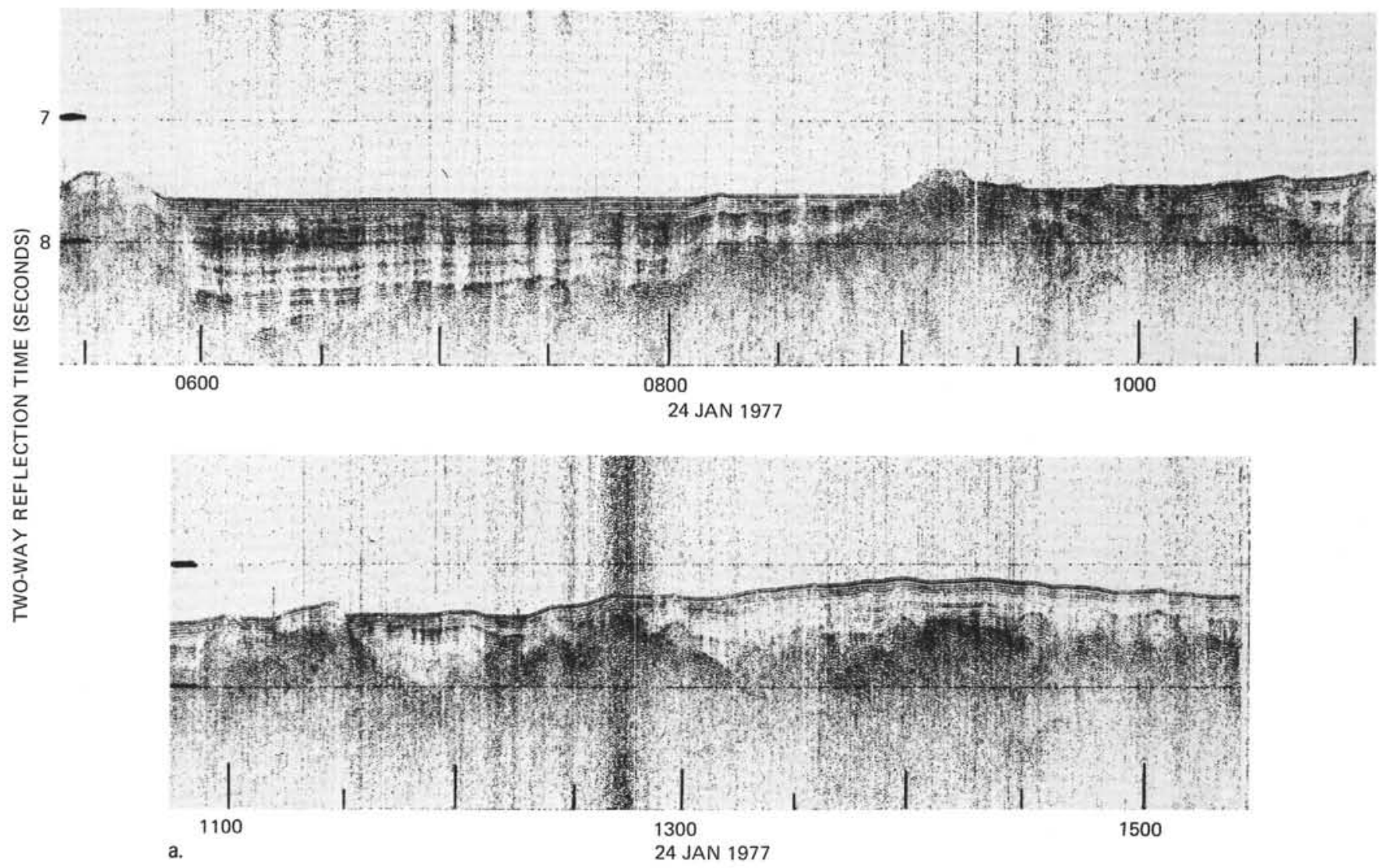

Figure 17 (a-c). Seismic reflection profiler records collected aboard D. V. Glomar Challenger, Leg 52. Vertical scale in seconds of two-way reflection time. Horizontal scale given in time along ships' tracks and is keyed to Figure 1. Free-firing airgun with repetition rate of $10 \mathrm{~s}$ used as sound source. 


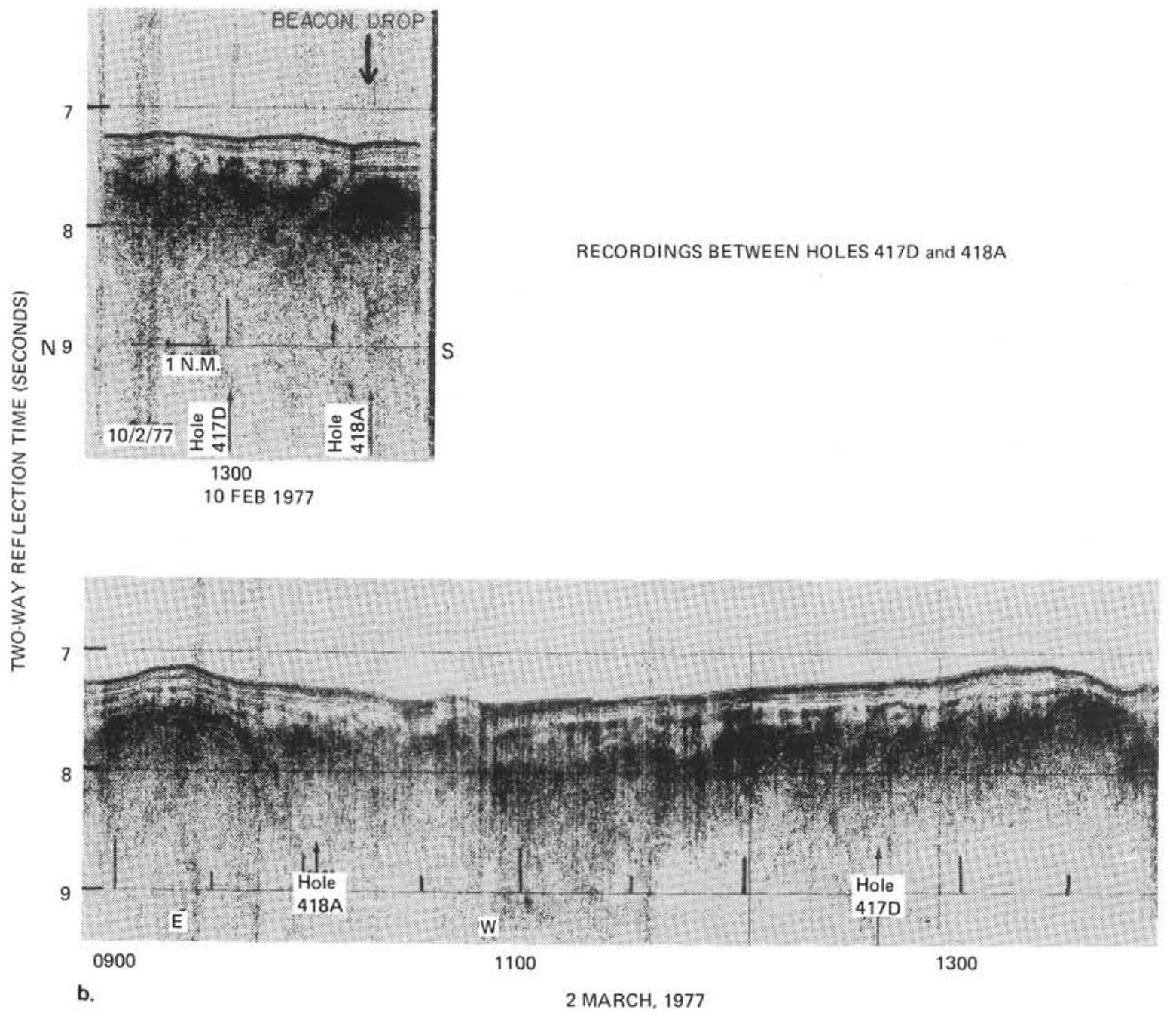

Figure 17. (Continued). 


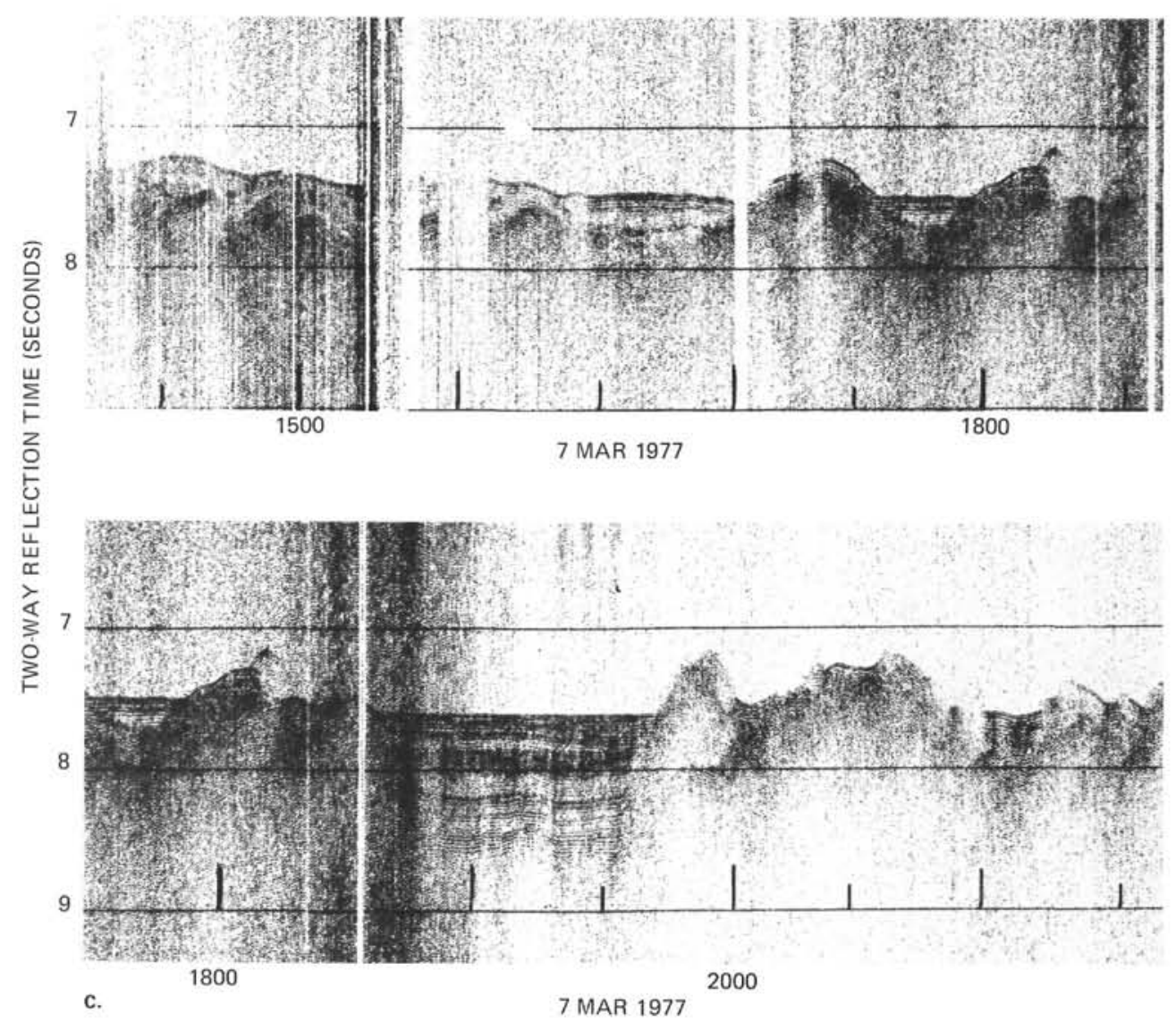

Figure 17. (Continued). 

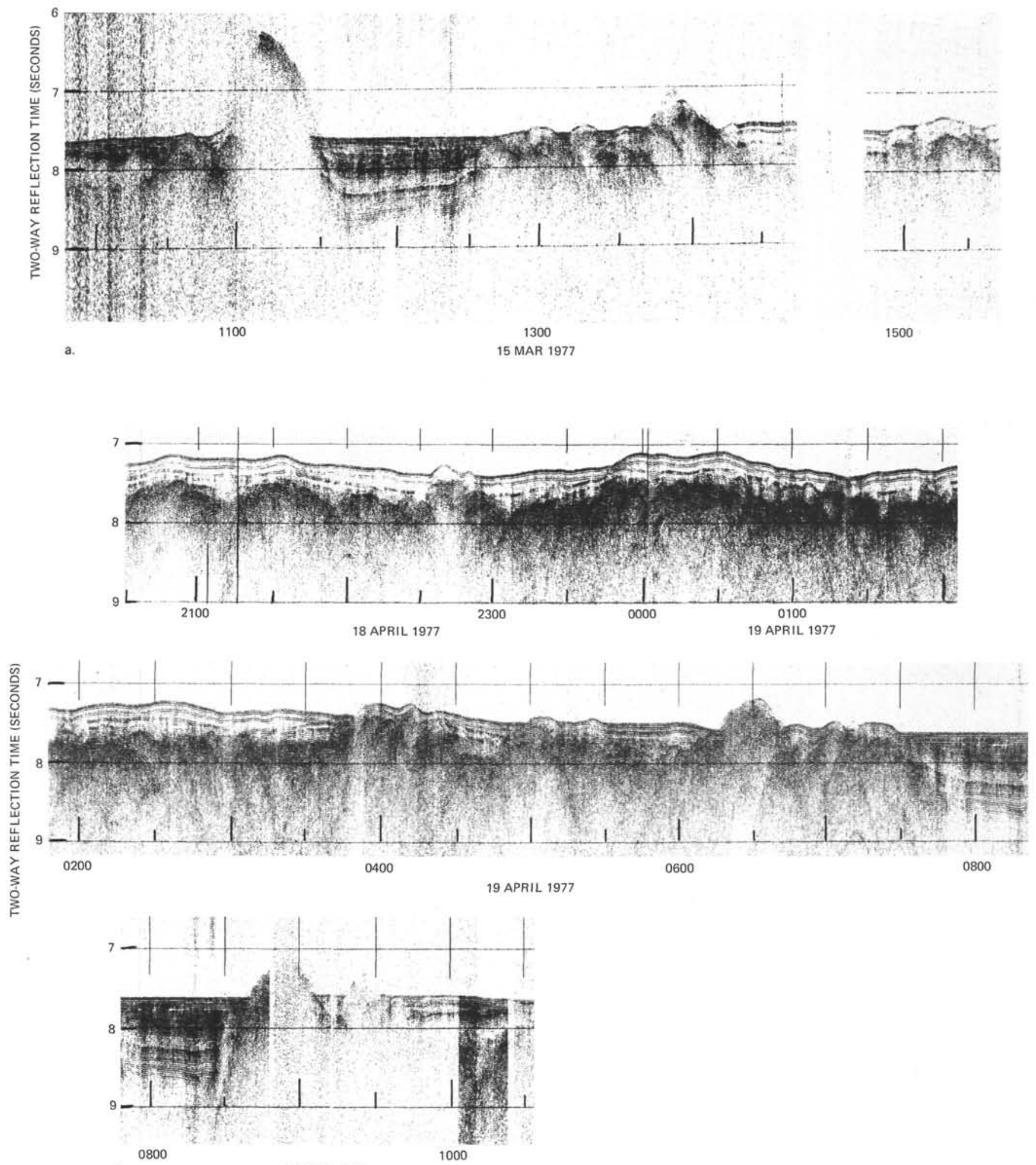

b. 19 APRIL 1977

Figure 18. (a,b) Seismic reflection profiler records collected aboard D. V. Glomar Challenger, Leg 53. Vertical scale in seconds of two-way reflection time. Horizontal scale given in time along ships' tracks and is keyed to Figure 1. Airgun with repetition rate of $10 \mathrm{~s}$ used as sound source. 